\title{
Analysis of Advanced Solar Hybrid Desiccant Cooling Systems for Buildings
}

Dennis Schlepp

Kenneth Schultz

October 1984

Prepared under Task No. 1600.23

FTP No. 443

Solar Energy Research Institute

A Division of Midwest Research Institute

1617 Cole Boulevard

Golden, Colorado 80401

Prepared for the

U.S. Department of Energy

Contract No. DE-AC02-83CH10093 
Printed in the United States of America Available from:

National Technical Information Service

U.S. Department of Commerce

5285 Port Royal Road

Springfield, VA 22161

Price:

Microfiche A01

Printed Copy Ȧ04

\section{NOTICE}

This report was prepared as an account of work sponsored by the United States Government. Neither the United States nor the United States Department of Energy, nor any of their employees, nor any of their contractors, subcontractors, or their employees, makes any warranty, express or implied, or assumes any legal liability or responsibility for the accuracy, completeness or usefulness of any information, apparatus, product or process disclosed, or represents that its use would not infringe privately owned rights. 


\section{PREFACE}

The objective for the Active Solar Heating and Cooling Program (U.S. Department of Energy) is to develop the technology base to allow the private sector to produce efficient, economically competitive solar technology options for the marketplace. The program encompasses a balance of research on systems, components, and materials. The systems research directs the program through analysis of alternative, advanced concepts in heating and cooling. Additionally, research in systems reliability provides data on critical components and materials that affect long-term performance. The analysis and reliability programs are augmented by a laboratory and field-test program that develops data on experimental and state-of-the-art systems. These data identify design and operational problems and, thus, opportunities for research.

The Component and Materials Program performs research on advanced concepts that have been identified by systems analysis to offer promise of being competitive with conventional, nonrenewable energy sources. Key components, such as chillers, dehumidifiers, heat exchangers, and collectors, are evaluated through modeling and testing to improve energy delivery competitiveness. Advanced materials for these key components are evaluated or modified to provide improved performance and lower cost.

This report presents an assessment of the energy savings possible from hybriddesiccant/vapor compression air conditioning systems and makes recommendations for continued research to develop high performance systems competitive with conventional cooling systems.

This work was performed under Task 1600.23, Desiccant Cooling Research, during FY 1983 with funding provided by the U.S. Department of Energy's Office of Solar Heat Technologies. The authors thank Terry R. Penney of SERI and John W. Mitchell of the University of Wisconsin for their constructive reviews of this work.

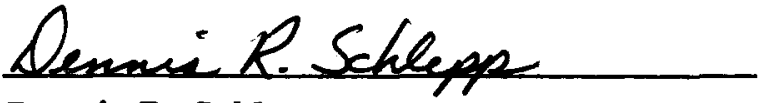

Dennis R. Schlepp

Approved for

SOLAR ENERGY RESEARCH INSTITUTE
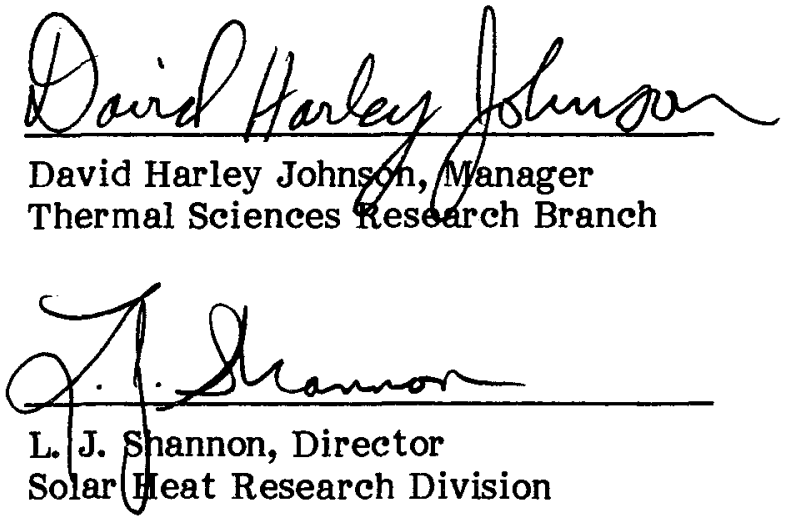


\section{SUMMARY}

\section{Objective}

This work assesses the energy savings possible from developing hybrid-desiccant/vaporcompression air conditioning systems and makes recommendations for further research into the concept.

\section{Discussion}

The idea of using desiccant dehumidifiers and vapor compression chillers to handle the latent and sensible loads of a building has been considered for years as technically possible but impractical with the state of the art in commercially available components. Recent advances in dehumidifier design for solar desiccant cooling systems have resulted in dehumidifier geometries with low-pressure drop and high efficiency in heat and mass transfer. These advances have prompted a new look at the hybrid concept.

A study was undertaken to investigate a number of hybrid system configurations for residential and small commercial applications. Dehumidifiers, heat exchangers, indirect evaporative coolers, and vapor compression chillers were arranged into four configurations to cover a range of design possibilities. The systems were sized to handle a $10-\mathrm{kW}$ (3-ton) air conditioning load at standard test conditions and then were analyzed for steady state performance over a wide range of ambient conditions.

\section{Conclusions and Recommendations}

All of the hybrid desiccant/vapor compression systems showed substantial savings in resource energy when compared to the best conventional systems with vapor compression. These savings ranged from $30 \%$ to $80 \%$, depending on the operating conditions.

The simplest system configuration, consisting of dehumidifier and vapor compression subsystems in series, was found to be the best overall performer. It is likely to be the least expensive to build and operate because of its simplicity. It is recommended that this configuration be investigated in seasonal simulation to evaluate its performance under transient load and operating conditions. Also, an experimental program to confirm the performance predicted in this study is recommended. 


\section{TABLE OF CONTENTS}

Page

1.0 Introduction $\ldots \ldots \ldots \ldots \ldots \ldots \ldots \ldots \ldots \ldots \ldots \ldots \ldots \ldots \ldots \ldots \ldots \ldots \ldots$

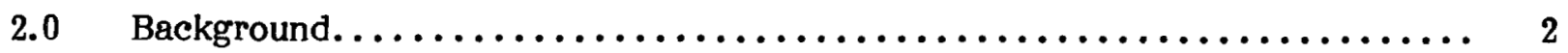

2.1 System Configurations .......................... 2

2.2 Current Status.................................. 4

$3.0 \quad$ System Studies. $\ldots \ldots \ldots \ldots \ldots \ldots \ldots \ldots \ldots \ldots \ldots \ldots \ldots \ldots \ldots \ldots \ldots \ldots \ldots$

3.1 Candidate Systems $\ldots \ldots \ldots \ldots \ldots \ldots \ldots \ldots \ldots \ldots \ldots \ldots \ldots \ldots \ldots \ldots \ldots$

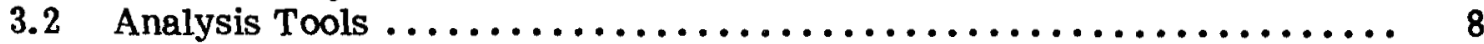

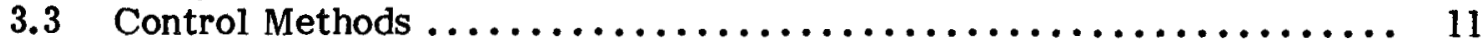

$4.0 \quad$ Results $\ldots \ldots \ldots \ldots \ldots \ldots \ldots \ldots \ldots \ldots \ldots \ldots \ldots \ldots \ldots \ldots \ldots \ldots \ldots \ldots$

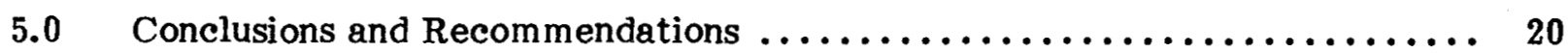

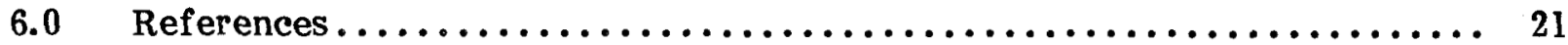

Appendix A Tabulated Study Results $\ldots \ldots \ldots \ldots \ldots \ldots \ldots \ldots \ldots \ldots \ldots \ldots \ldots \ldots 22$ 


\section{LIST OF FIGURES}

Page

2-1 Psychrometric Representation of Vapor Compression, Adiabatic Desiccant Dehumidifier, and Hybrid System Cooling Processes ........... 3

2-2 Hybrid System Configuration for Supermarket Application ............ 4

2-3 Liquid Desiccant Hybrid Cooling System.................... 5

2-4 Hybrid System for Small Office Building Applications .............. 6

3-1 System 1 Basic Hybrid $\ldots \ldots \ldots \ldots \ldots \ldots \ldots \ldots \ldots \ldots \ldots \ldots \ldots \ldots \ldots \ldots \ldots$

3-2 System 2 Hybrid with Heat Recovery $\ldots \ldots \ldots \ldots \ldots \ldots \ldots \ldots \ldots \ldots \ldots \ldots$

3-3 System 3 Hybrid with Environmental Cooling................... 10

3-4 System 4 Hybrid with Heat Receiver and Environmental Cooler......... 11

3-5 Range of Outdoor Conditions Encountered in Air-Conditioning......... 13

3-6 Outdoor Conditions for System Studies with State Points ............ 13

4-1 Performance Map of Hybrid System 1 for Varying Outdoor Conditions ...... 15

4-2 Performance Map of Hybrid System 2 for Varying Outdoor Conditions ...... 15

4-3 Performance Map of Hybrid System 3 for Varying Outdoor Conditions ...... 16

4-4 Performance Map of Hybrid System 4 for Varying Outdoor Conditions ...... 16

4-5 System Performance Comparisons at Varying Dry Bulb Temperatures with Humidity Ratio $=0.012 \mathrm{~g} \mathrm{H}_{2} \mathrm{O} / \mathrm{g}$ air $\ldots \ldots \ldots \ldots \ldots \ldots \ldots \ldots \ldots \ldots \ldots \ldots \ldots$

4-6 System Performance Comparisons at Varying Dry Bulb Temperatures with Humidity Ratio $=0.014 \mathrm{~g} \mathrm{H}_{2} \mathrm{O} / \mathrm{g}$ air........................... 17

4-7 System Performance Comparisons at Varying Dry Bulb Tempertures with

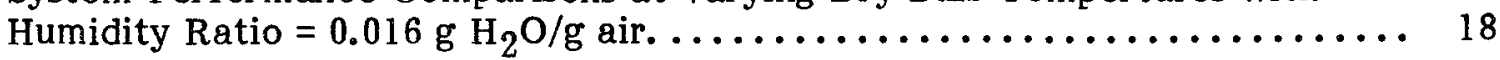

4-8 System Performance Comparisons with Varying Humidity Ratios Dry Bulb Temperature $=33^{\circ} \mathrm{C} \ldots \ldots \ldots \ldots \ldots \ldots \ldots \ldots \ldots \ldots \ldots \ldots \ldots \ldots \ldots$

4-9 System Performance Comparisons with Varying Humidity Ratios at Dry Bulb Temperature $=35^{\circ} \mathrm{C} \ldots \ldots \ldots \ldots \ldots \ldots \ldots \ldots \ldots \ldots \ldots \ldots \ldots \ldots \ldots$ 


\section{SECMON 1.0}

\section{INTRODUCTION}

Over the past several years, the (U.S Department of Energy) Active Heating and Cooling Program has sponsored research to develop competitive solar for cooling buildings. Part of this research program investigated combinations of dehumidification and evaporative cooling in solar-driven hybrid desiccant cooling systems. Desiccant cooling offers advantages as an option for building air conditioning, including use of low-temperature solar heat as the driving energy source, a broad range of residential and commercial building applications, and minimal initial cost with simple and inexpensive operation.

The research has focused on understanding and improving the heat and mass transfer characteristics of the dehumidifier component of desiccant cooling systems. In line with this effort the study evaluated the steady-state performance of hybrid desiccant/vapor compression systems, in a number of configurations, and compared the use of resource energy to that of conventional air-conditioning systems. This study will evaluate the potential for developing hybrid systems by using current knowledge in dehumidifier design and will point the way for further research, if warranted. 


\section{SECTION 2.0}

\section{BACKGROUND}

\subsection{SYSTEM CONFIGURATIONS}

In general, the best solutions to complex problems use appropriate technology that combines the features of several processes that meet the needs of the application. Combining vapor compression cooling and desiccant dehumidification to air-condition buildings is one example of this approach. As outlined in an earlier report [1], this combination uses the best features of each to meet the cooling requirement.

Building loads have two components: sensible load and latent load. The sensible load results from heat gain from high ambient air temperatures, solar and internal heat sources and requires lowering the temperature of the building air. Latent load involves lowering the humidity ratio of the air in the building and balancing the moisture gain from humid air entering the building and the gain from internal sources.

Vapor compression systems are very good at providing sensible cooling. By having building air circulate over a chilled coil, the heat transfer from the air to the refrigerant effectively lowers the air temperature. However, when the vapor compression system has to handle the latent load as well, the only method available is to cool the air past its dew point and remove the excess moisture. To do so, the system must operate at a coil temperature of $2^{\circ}-7^{\circ} \mathrm{C}\left(35^{\circ}-45^{\circ} \mathrm{F}\right)$, reducing the efficiency of the system. In addition, to maintain the building at a comfortable state, the air leaving the evaporator of the vaporcompression system must be reheated to the inlet state air temperature to maintain equilibrium in the building. Figure 2-1a illustrates the processes involved on a psychrometric chart for the commercial application where reheat is involved.

Desiccant cooling systems are very good at providing latent cooling by reducing the humidity ratio of building air. However, when the desiccant cooling system must handle the entire load, it overdries the process air so evaporative cooling can be used for the sensible cooling. A typical recirculation cycle for the desiccant cooling system is shown in Figure 2-1b.

Combining the ability of the desiccant dehumidifier to handle the latent load and the ability of the vapor compression subsystem to meet the sensible cooling load leads to a very efficient system. The dehumidifier subsystem needs to remove only enough moisture to satisfy the building's needs, thereby reducing the size of the dehumidifier and lowering the required regeneration temperature from the $70^{\circ}$ to $80^{\circ} \mathrm{C}$ needed by the desiccant cooling system to $50^{\circ}$ to $60^{\circ}$ for the hybrid system. The vapor compression subsystem needs only to cool the process air to the required supply temperature and not to the dew point temperature. As a result, the coil temperature can be raised from $7^{\circ}$ to $13^{\circ} \mathrm{C}$, which increases the efficiency of the system. The combination can be further enhanced by using the heat rejected by the condenser of the vapor compression subsystem to help regenerate the desiccant in the dehumidifier. This synergistic action makes the hybrid system an energy efficient alternative to conventional building airconditioning systems. The processes of the hybrid system are shown on a psychrometric chart in Figure 2-1c. 


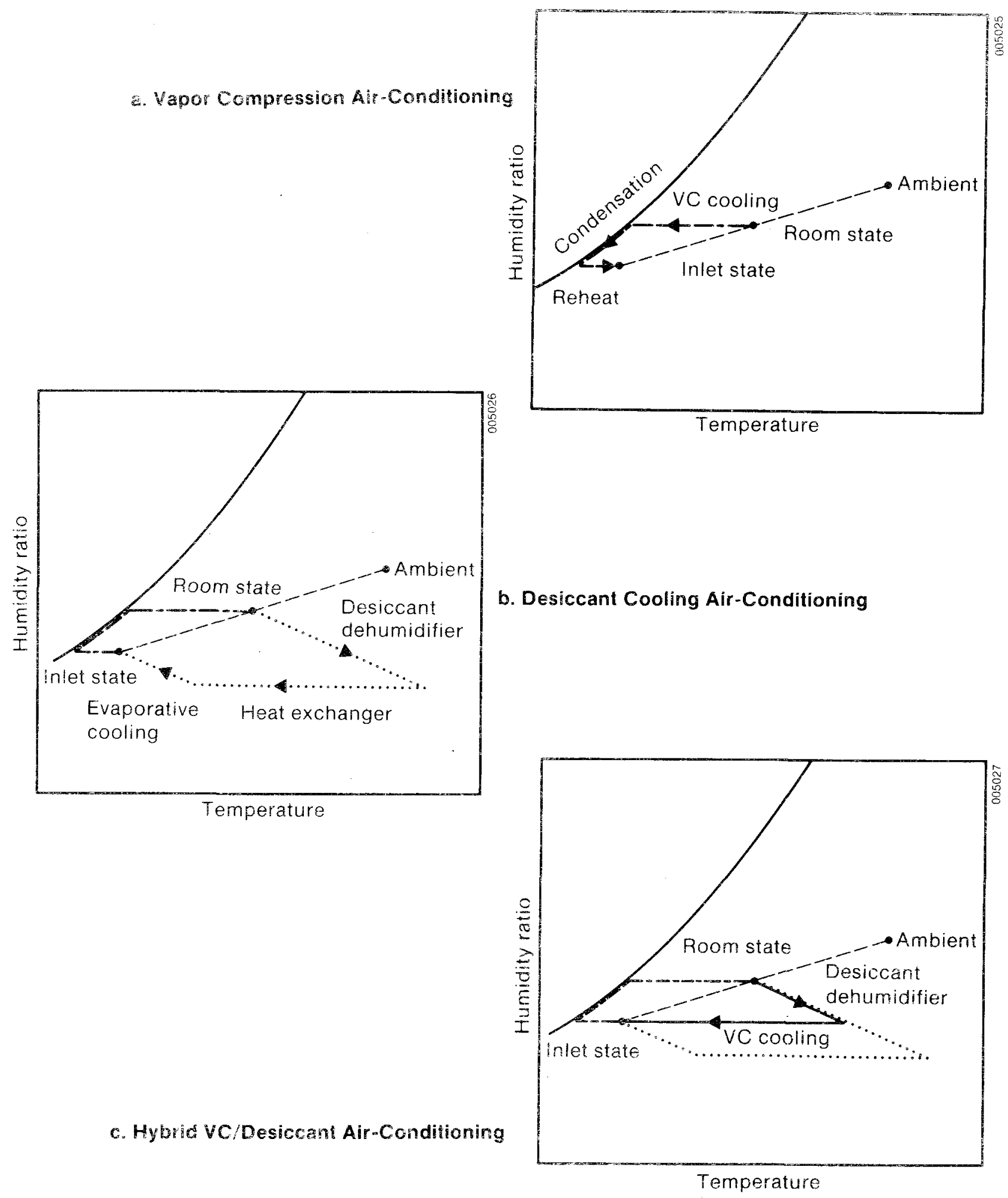

Figure 2-1. Psychrometric Representation of Vapor Compression, Adiabatic

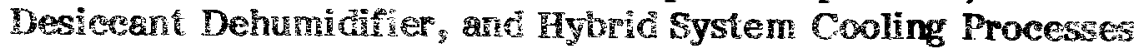




\subsection{CURRENT STATUS}

The desiccant cooling systems discussed in Section 1.0 were proposed for residential applications; most of the hybrid systems proposed to date were for commercial applications.

A cooperative effort among ThermoElectron, Gas Research Institute (GRI), and Jewell Supermarkets resulted in the installation of a hybrid system in a Jewell store [2]. In a food store much of the sensible cooling is provided by the freezer and refrigeration cases. Additional dehumidification is often required, however. By using a desiccant dehumidifier to remove this moisture, the size of the vapor compression unit and the electrical power consumed can be reduced substantially. Additionally, the freezer and refrigeration cases can be operated more efficiently because less frost builds up.

The simple configuration of the components shown in Figure 2-2 is used in the Jewell store. An adiabatic silica gel dehumidifier is used to dry ambient ventilation air. After passing through a heat exchanger to remove a portion of the heat of adsorption, the ventilated air is mixed with recirculated air and is sensibly cooled by the air conditioner to the required inlet temperature. Many problems were encountered during the first year of operation, yet results definitely indicated reduced energy use and economic viability. System performance and control remain to be optimized as the study continues. A similar system has been installed by Cargocaire in another supermarket [2].

Hybrid systems can also use liquid desiccant dehumidifiers. Gershon Meckler designed and installed the system shown in Figure 2-3 in a Veterans Administration Hospital [3]. Outside ventilation air is dried by contact with a lithium chloride solution (with external cooling) and passed to the vapor compression unit. The solution is regenerated by heating it with solar energy or recovered waste heat and by subsequent contact with a

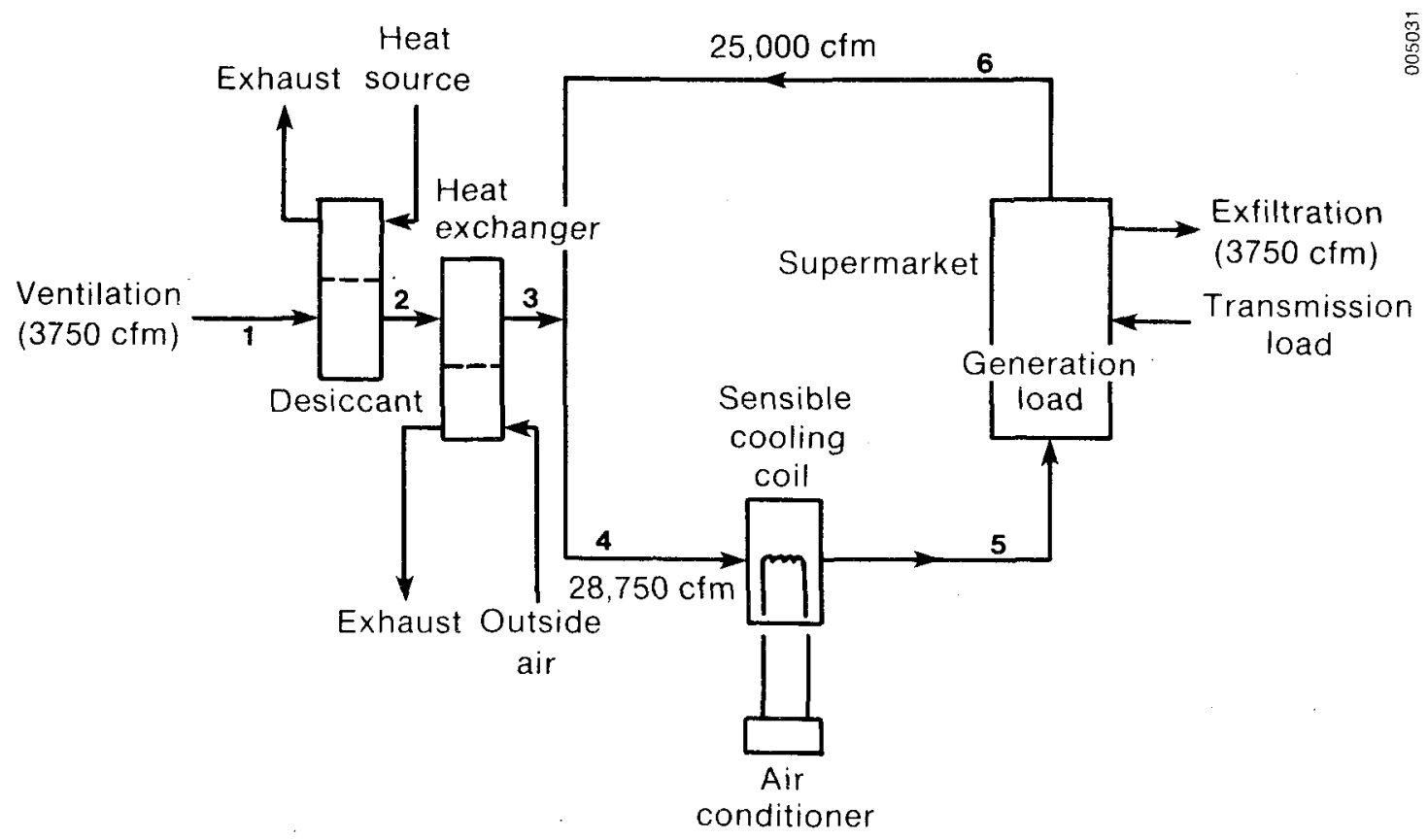

Figure 2-2. Hybrid System Configuration for Supermarket Application 

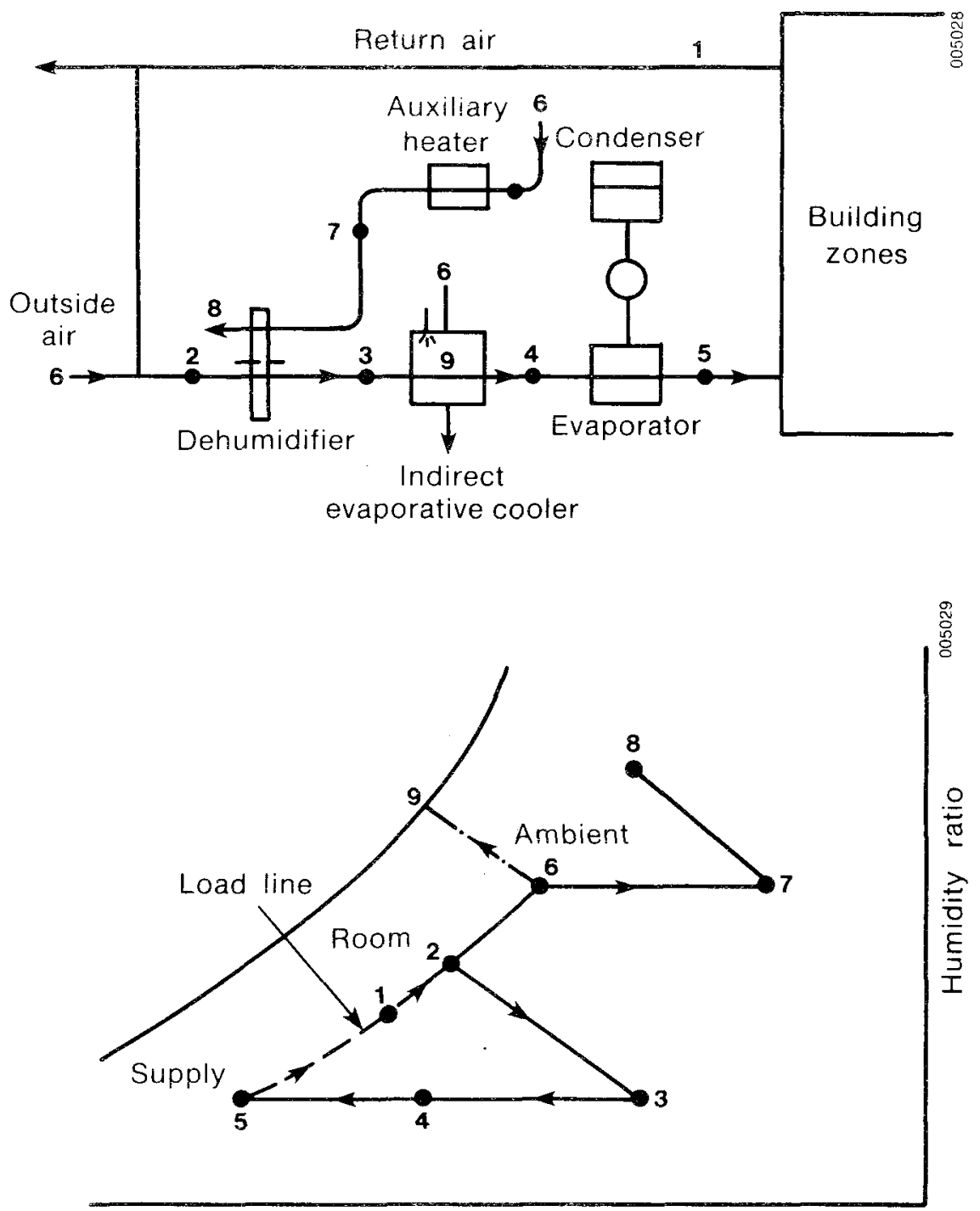

Temperature

Figure 2-3. Liquid Desiceant Hybrid Cooling System

heated air stream. This hybrid system is expected to reduce building cooling costs by $25 \%-50 \%$.

Current installations are in specialized applications because of unique cooling requirements and favorable economics. Researchers have analyzed a hybrid system for general applications in small office buildings $[4,5,6]$. The system has an adiabatic silica gel dehumidifier and is shown in Figure 2-4. Room air (1) is mixed with the required amount of ventilation air (6) and dehumidified air (3). The air is then cooled (4) to near the ambient wet-bulb temperature (9) in an indirect evaporative cooler. This system removes much of the cooling load from the vapor compression unit and is thermally "free" cooling. The dehumidifier is regenerated by using combinations of solar energy, 


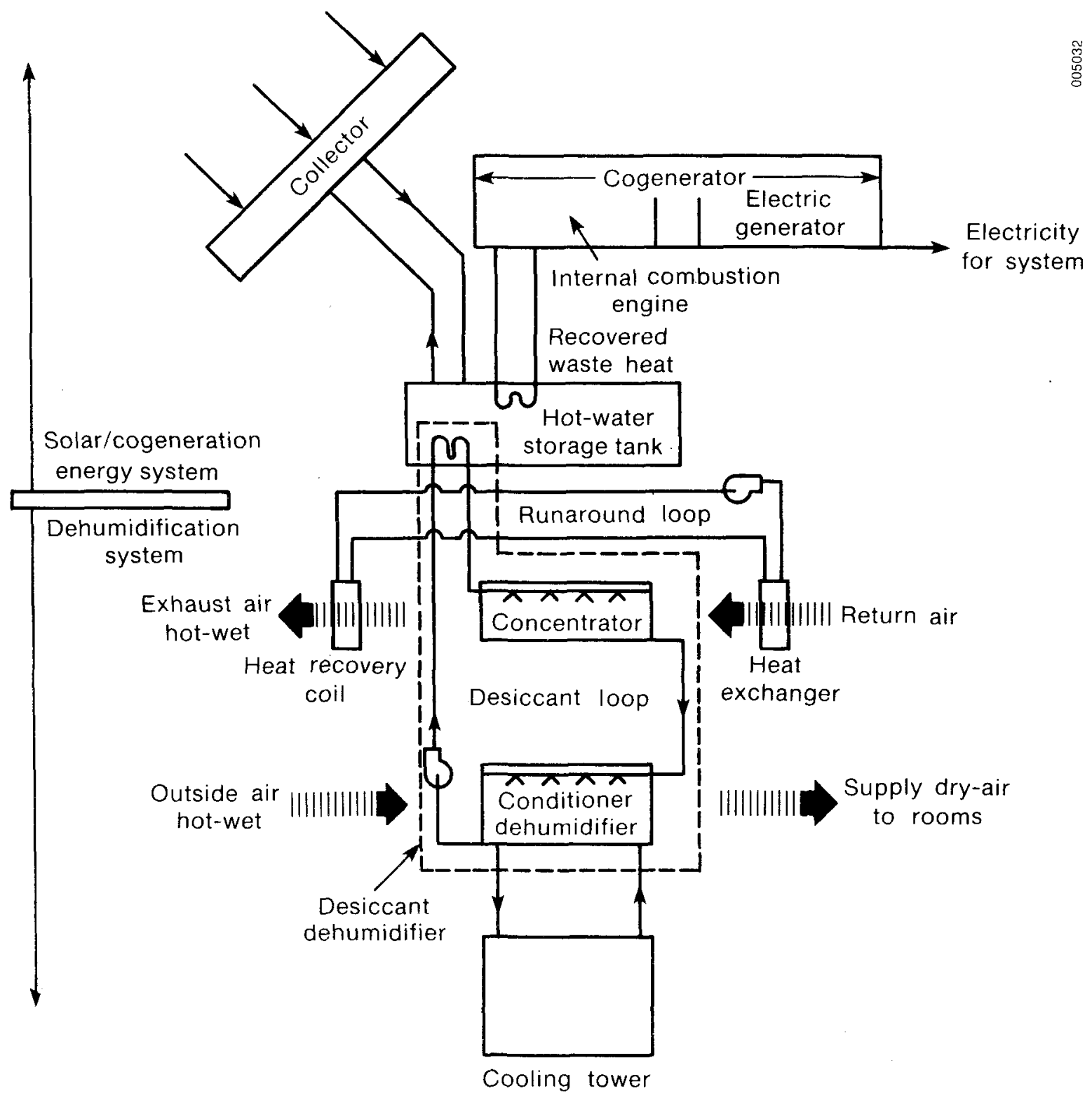

Figure 2-4. Hybrid System for Small Office Building Applications

condenser waste heat, and auxiliary energy. Simulations of this hybrid system show that resource energy consumption can be reduced to $35 \%-55 \%$ of that used by a standard vapor compression system $[5,6]$. The reduction depends on how much cooling can be obtained from the indirect evaporative cooler. The indirect evaporative cooler is very effective in dry climates, and energy savings can be large.

The current supermarket installations do not include solar energy systems and the simulations of solid desiccant hybrid systems for general applications were not favorable to solar because most of the regeneration energy can be supplied by the condenser rejection heat. Systems using liquid desiccants are particularly suitable for solar regeneration. Many problems concerning system performance and control remain to be worked out; yet, it is very cncouraging that the hybrid systems discussed here were designed and installed in commercial settings where economics are a major factor. 


\section{SECIION 3.0}

\section{SYSTEM STUDIFS}

\subsection{CANDIDATE SYSTEMS}

In analyzing the performance characteristics of hybrid systems we found several choices of configuration. Several components can be incorporated into the system to take advantage of waste-heat recovery and environmental cooling. Each of these components, such as heat exchangers and evaporative coolers, has advantages and disadvantages in cost and performance.

To limit the breadth of the study, we made some assumptions about the type of hybrid system that could eventually be commercially competitive. First, the systems to be considered would be limited to residential and small commercial sizes of 10 to $80 \mathrm{~kW}$ ( 3 to 25 tons) of cooling. Because the study uses laboratory-validated technology in solid desiccant dehumidifiers, the practical limit for single-unit systems is determined by the size of heat exchanger and dehumidifier wheels. To date, these units have been constructed in sizes up to equivalent capacities of $80 \mathrm{~kW}$. Second, the candidate systems must use standard industrial equipment for the vapor compression subsystems and place upper limits on evaporator and condenser temperatures $\left(13^{\circ} \mathrm{C}\right.$ and $60^{\circ} \mathrm{C}$, respectively). Third, the systems considered should be simple. Although they will use energy-saving components as much as possible, only one level of heat recovery or environmental cooling will be used to minimize expense and control problems. System control and operating strategies are discussed in subsequent sections.

Using these basic assumptions, we chose four candidate systems for study:

1. Basic hybrid desiccant/vapor compression system. As shown in Figure 3-1, the basic hybrid system combines desiccant dehumidifier and vapor compression subsystems in series, with the vapor compression condenser and auxiliary heat source providing regeneration heat for the dehumidifier. The psychrometric process for this candidate system is shown in Figure 3-1.

2. Hybrid desiccant/vapor compression system with heat recovery. Figure 3-2 shows the second candidate system, which includes a heat exchanger to remove part of the heat of adsorption from the cooled air stream and to use it to preheat the regeneration air stream. Figure 3-2 depicts the process path on a psychrometric chart.

3. Hybrid desiccant/vapor compression system with environmental cooling. An indirect evaporative cooler is used to cool the process air stream to reduce the load on the vapor compression evaporator. Ambient air is evaporatively cooled and then used in an air-to-air heat exchanger to lower the temperature of the cooled air (Figure 3-3). The process path, including the evaporative cooling process (dashed line), is shown in Figure $3-3$.

4. Hybrid desiccant/vapor compressions system with heat recovery and environmental coolng. This configuration uses boh the heat recovery wheel and indirect evaporative cooler to push the energy efficiency as far as possible. The system layout is shown in Pigure $3-4$ with the key process paths shown in Figure $3-4$. 

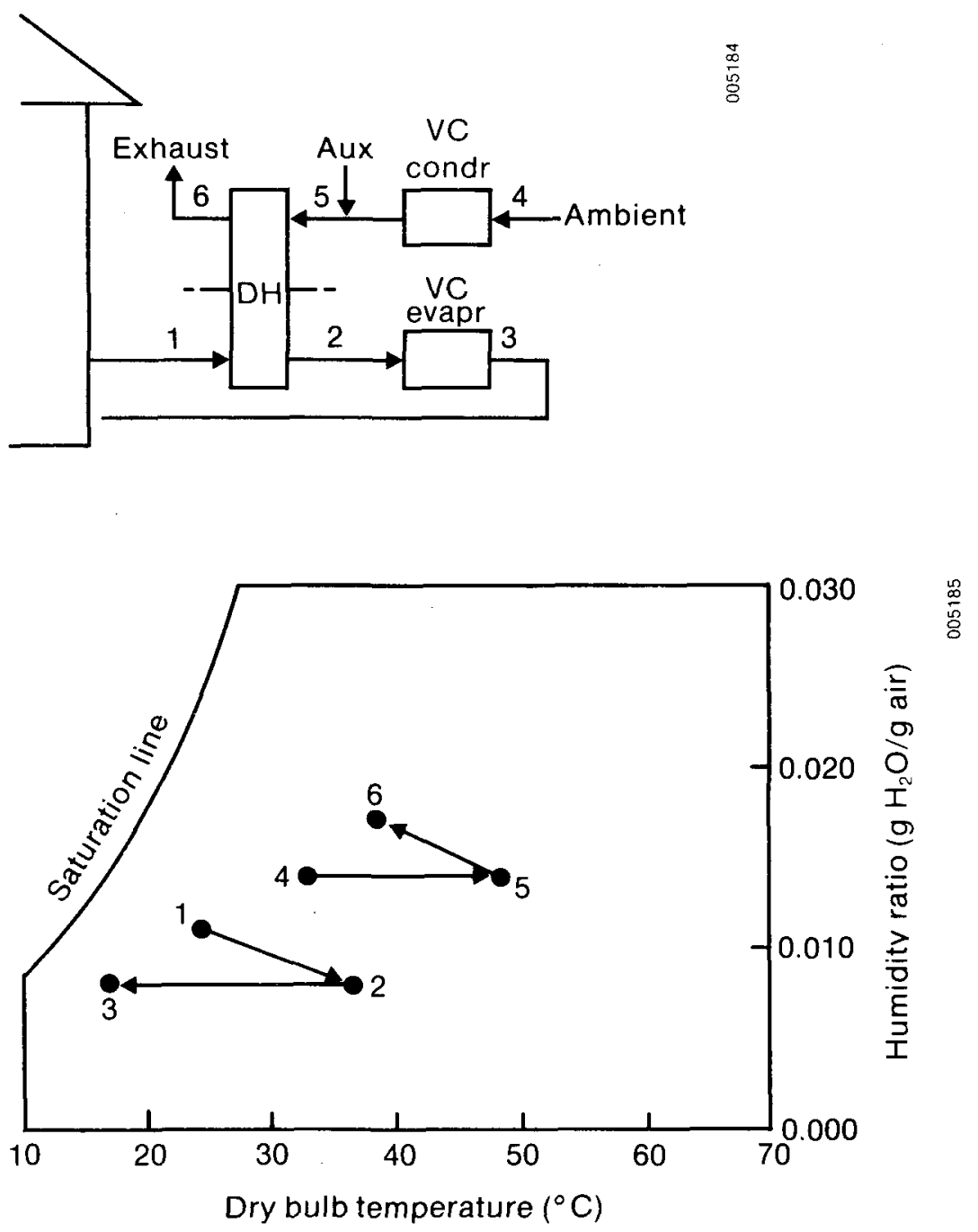

Figure 3-1. System 1 Basic Hybrid

We studied the design-point performance of each of these systems at a number of operating conditions. This approach identified possible high-performance configurations meriting further study regarding system integration, control, and operating economics.

\subsection{ANALYSIS TOOLS}

To analyze the performance of the desiccant/vapor compression hybrid systems, we needed to define the analysis tools that could evaluate the steady-state performance of the components and systems. The key component, the dehumidifier, was modeled with laboratory validation by the DESSIM computer model. Also, we used the MOSHMX 

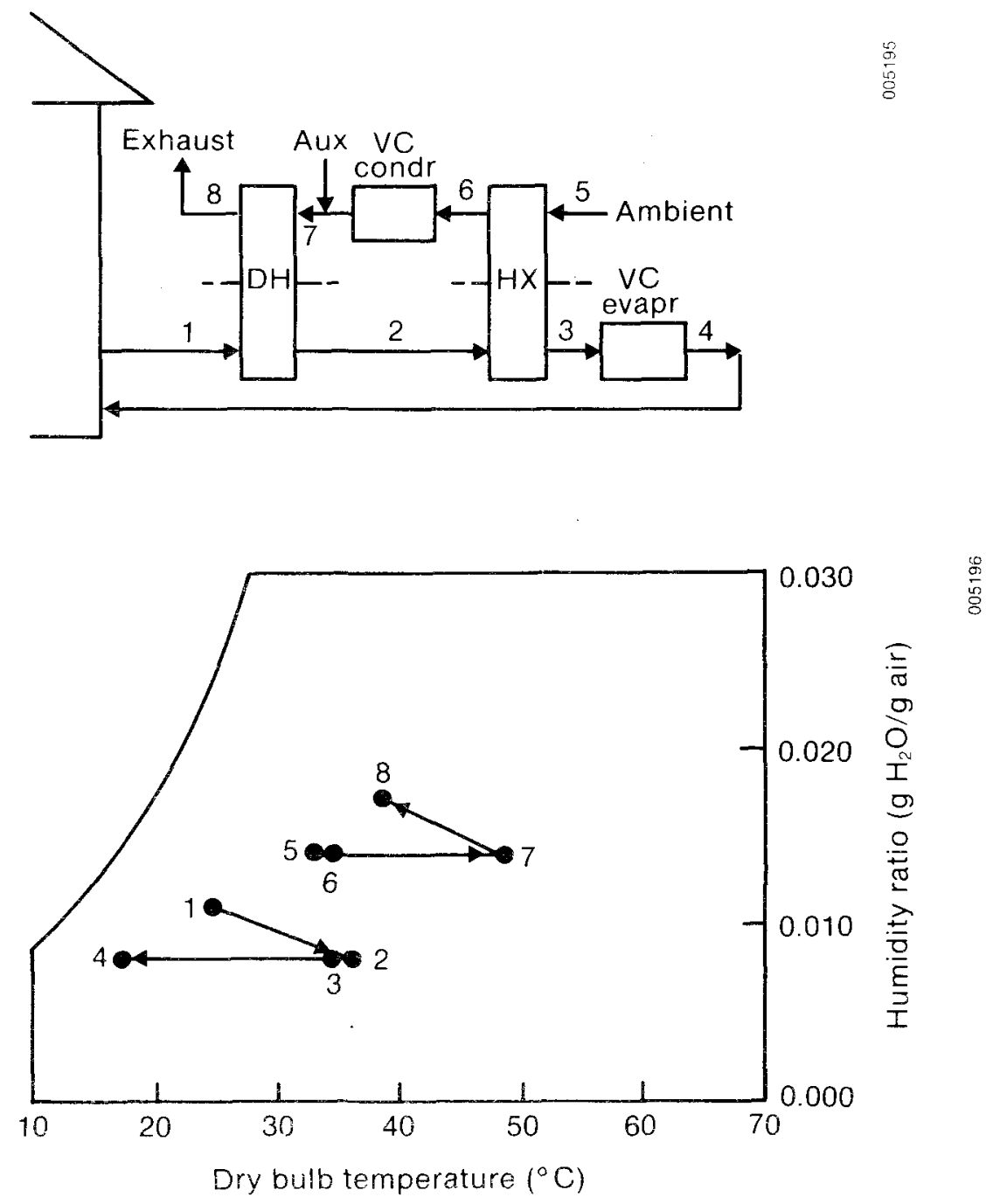

\section{Figure 3-2. System 2 Fybrid with Heat Recovery}

finite-difference model for heat and mass transfer to indepencently verify test runs. We used both models to predict the behavior of the parallel-passage dehumidifier operating in a hybrid-desiccant/vapor-compression system.

We modeled the performance of the vapor-complession subsystem using manufacturer"s data from Camier Corporation. These data urovided information about the relative efficiency of the subsystem with changes in evaporator and condenser temperatures. Carl Bergt of Trane Co. (Sherman, Tex.) provide valuabie information on the limitation of vapor-compression cycles in hybrid-system operation. 

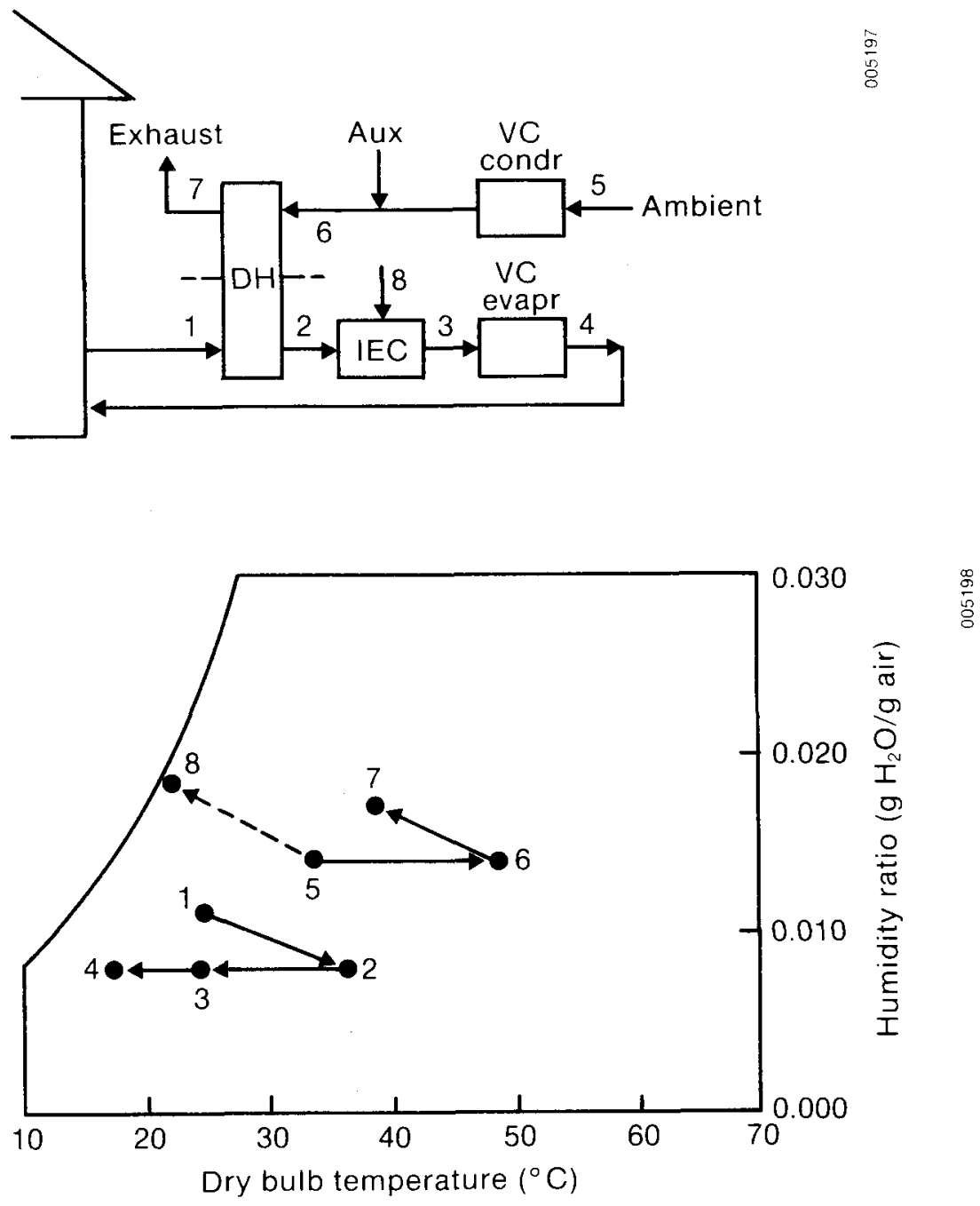

Figure 3-3. System 3 Hybrid with Environmental Cooling

The heat recovery wheel used in two of the systems was modeled using information from tests with parallel-passage heat exchangers conducted at Monash University (Australia) [7]. These heat exchangers have an effectivenesses of up to $93 \%$. The data from these tests were used to determine the efficiency of the heat recovery at process conditions.

Performance data on the indirect evaporative cooler were obtained from the work of Pescod [8] on a plate-type cross-flow heat exchanger in which one of the air streams is evaporatively cooled by spraying water in the channel. This arrangement provides a low sink temperature for the other air stream. An effectiveness of $90 \%$ was assumed in this analysis. More detailed analysis is required in subsequent studies. 

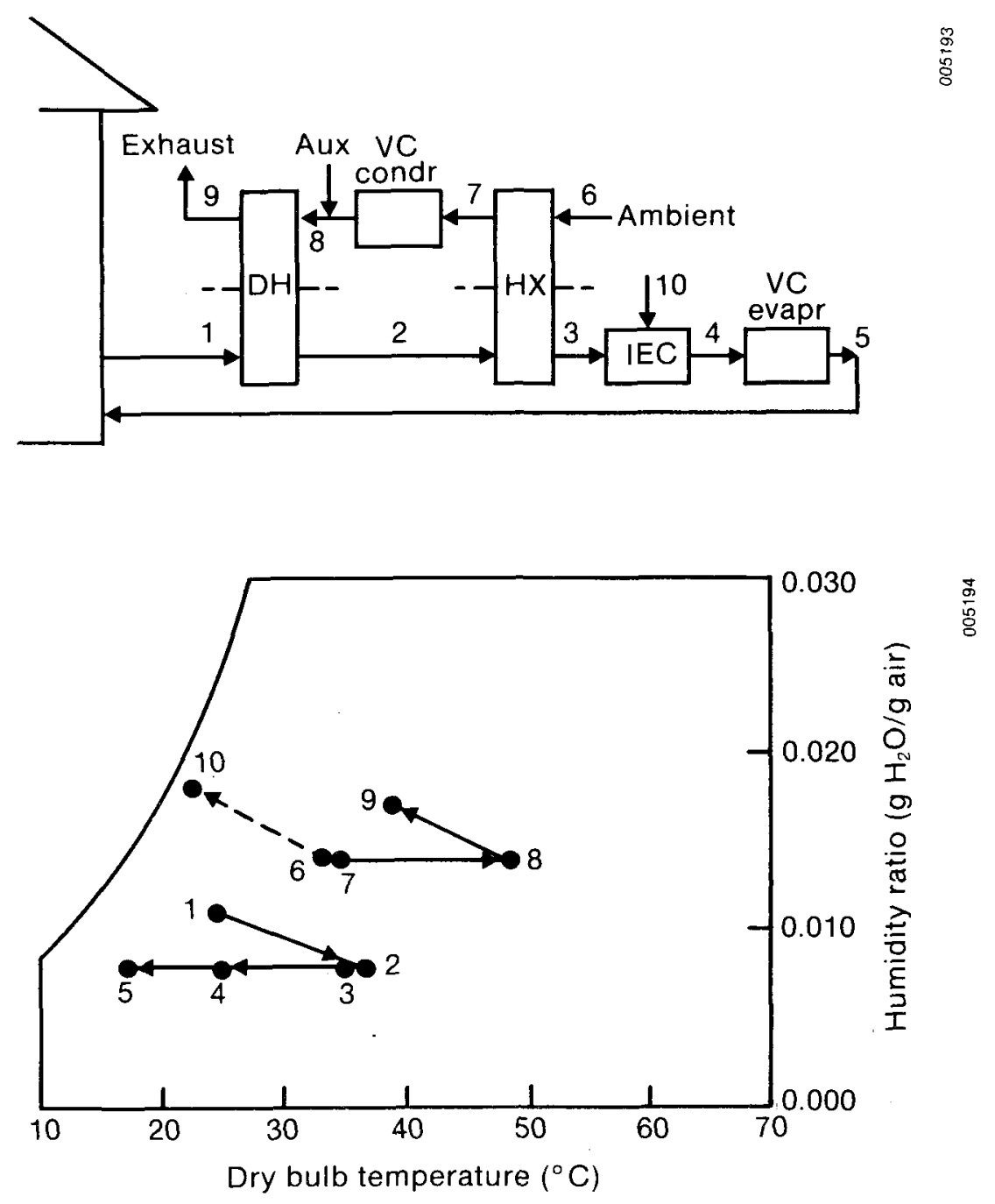

Figure 3-4. System 4 Hybrid with Heat Receiver and Environmental Cooler

\subsection{CONTROL METHODS}

In modeling the hybrid systems it was necessary to define analysis state points, control strategies, and primary and secondary control parameters that the model would use to define state point conditions.

The state points selected for the study are ranges of ambient conditions found in three cities representing different climates and cooling loads: Miami, Fla., Columbia, Mo., and Phoenix, Ariz. In a study of cooled-bed desiccant cooling cycles, Schultz [9] analyzed TMY (typical metorological year) profiles of hourly weather data to define regions of state conditions that could be encountered in these three cities (see Figure 3-5). From 
the regions defined in this study an analysis of the operation of the hybrid system showed that the region of temperature and humidity above the ARI design point would be critical to the analysis of the recirculation hybrid cycle, as shown in Figure 3-6. The points in this region are the ambient state points used for this study.

To keep the systems as realistic as possible and to conform to industry practice, we made several assumptions about the control methods for the hybrid system. Each component requires an independent control subsystem since the system as a whole requires controls. For the desiccant dehumidifier the primary control is regeneration temperature. Since the dehumidifier will be called on to handle a variety of humidity levels, the regeneration temperature and, consequently, the capacity of the dehumidifier are most important to the hybrid system. Other parameters, such as the rotation speed and air flow rate, are less desirable as controls since they exhibit high input and output ratios on the control of outlet humidity ratio. The regeneration temperature of the air exiting the vapor compression condenser is limited to $58^{\circ} \mathrm{C}\left(2^{\circ} \mathrm{C}\right.$ approach to the $60^{\circ} \mathrm{C}$ condenser operating temperature); so operating conditions requiring regeneration temperatures above $58^{\circ} \mathrm{C}$ require auxiliary sources such as solar-generated thermal sources.

Standard modulating methods control the vapor compression subsystem down to $50 \%$ of rated capacity, which is the practical limit for commercial systems. Operation below that point would be controlled by cycling or bypassing.

Another industrial standard included in the simulation is to change the process flow rate as the load goes over the rated capacity of the unit. In this case the standard flow rate of $0.67 \mathrm{~kg} / \mathrm{s}$ for $10 \mathrm{~kW}$ of cooling (1200 scfm for 3 tons of cooling) is increased by $25 \%$ to $0.84 \mathrm{~kg} / \mathrm{s}(1500 \mathrm{sefm})$ to handle higher cooling loads.

In all cases these assumptions ensure that system studies reflect performance in common HVAC installations. Flow rates, fan and duct sizes, and control methods are consistent with industrial practice. Also, the results can be extrapolated to auxiliary heat sources (such as waste heat) other than solar heat input. The system only recognizes that a heat source with a temperature of $60^{\circ} \mathrm{C}$ and above is present and able to supply sufficient heat for regeneration. 


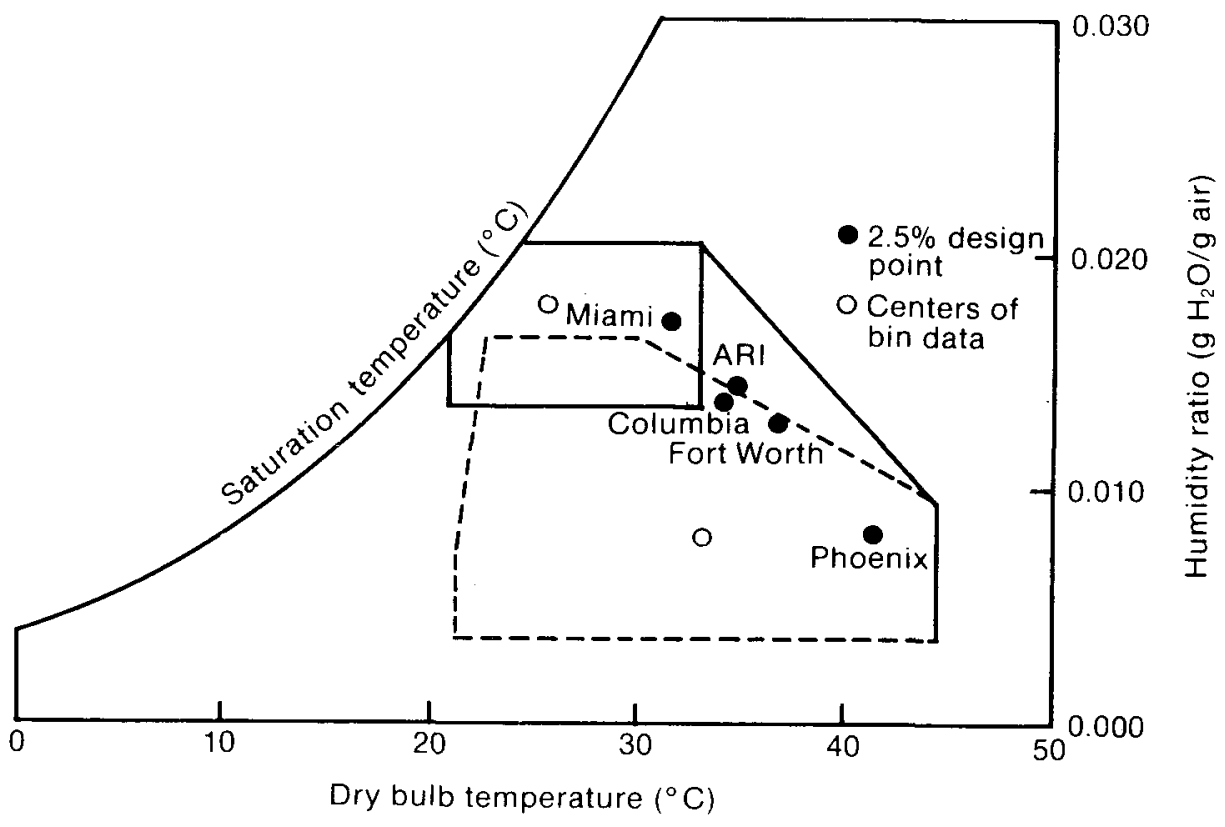

Figure 3-5. Range of Outdoor Conditions Encountered in Air-Conditioning

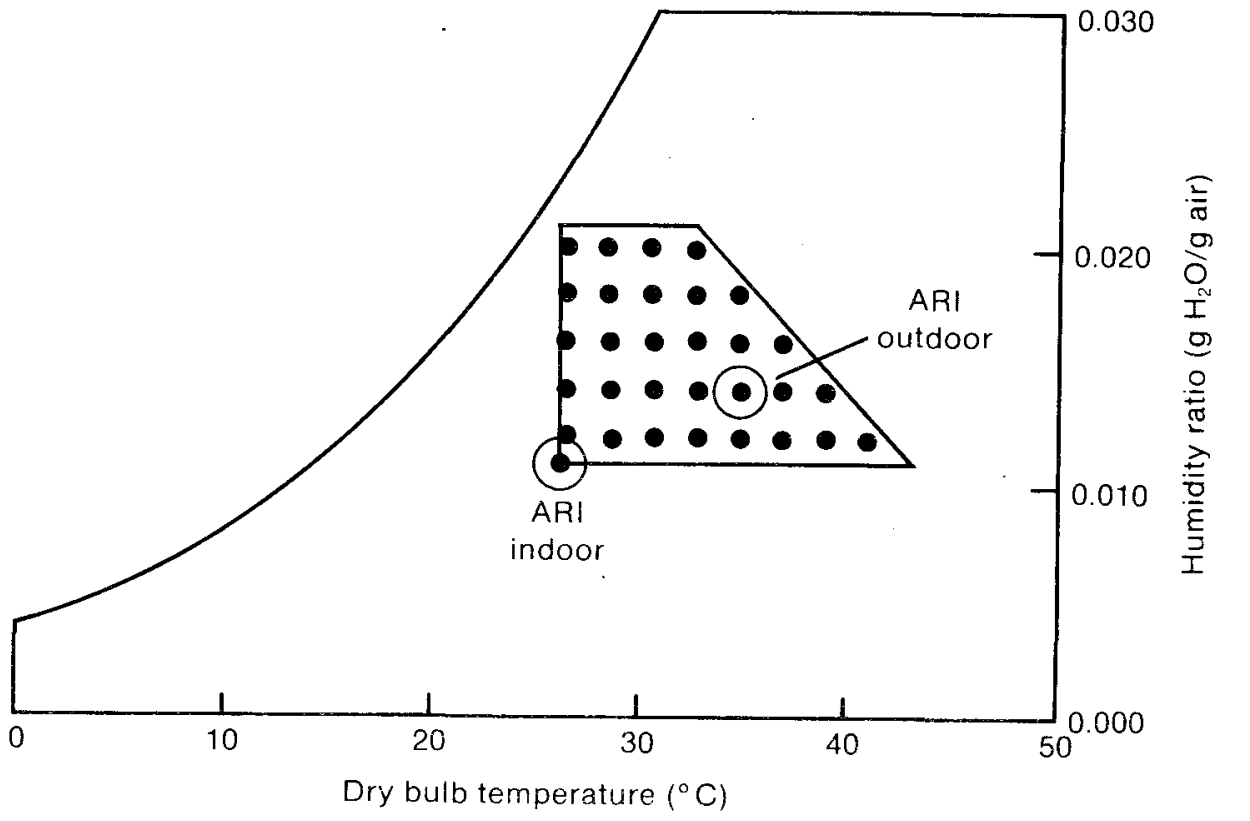

Figure 3-6. Outdoor Conditions for System Studies with State Points 


\section{SECTION 4.0}

\section{RESULTS}

The results of modeling the four hybrid systems are shown in Figures 4-1 through 4-4 as performance maps over the range of outdoor conditions discussed in Section 3.0. The graphs compare the power ratio of the energy consumption of the hybrid system with the energy consumption of the conventional competition, a heat pump with a cooling coefficient of $3.0 \mathrm{~kW} / \mathrm{kW}$.

The performance maps show that, in general, the hybrid systems can save from $10 \%$ to $90 \%$ of the electric consumption of a conventional system, depending on the operating conditions. The range of conditions near the ARI outdoor design condition $\left(35^{\circ} \mathrm{C}\right.$, $0.014 \mathrm{~g} / \mathrm{g}$ ) shows a plateau of performance values of $60 \%$ to $80 \%$ savings with the performance changing significantly as the conditions range to extremes of a higher ratio in humidity and temperature. Since the nature of this study was to define a system of given size and determine its performance over a range of conditions, one expects the system to perform best around its design point (the ARI state point) and to suffer in performance as the conditions were driven farther from design. However, the systems were able to save energy in almost every area of study.

To make some qualitative judgments among the different system configurations, we compared the systems at certain points around the design point with varying temperatures at a fixed humidity ratio. These comparisons are shown in Figures 4-5 through 4-9. As discussed earlier, System 1 is the basic hybrid configuration with the desiccant dehumidifier in series with the vapor compression system using condenser waste heat to regenerate the dehumidifier. System 2 adds a heat recovery wheel; System 3 includes an indirect evaporative cooler; and System 4 includes both the heat exchanger wheel and the indirect evaporative cooler.

In comparing Systems 1 and 2 the effect of adding the heat exchanger is a benefit only at temperatures and humidities above the design point. Indeed, it is the same or lower in performance at all other points. This is because the temperature levels and differences present in the cycle are small and afford little benefit as preheat for the regeneration process. Therefore, adding a heat exchanger, critical to the desiccant cooling system, is not a benefit to the hybrid system and should not be part of a recirculation hybrid system.

The comparison of Systems 1 and 3 is more interesting from a system design standpoint. In previous studies $[4,5,6]$ the indirect evaporative cooler was found to be an essential part of a successful commercial hybrid system. In this study this conclusion is substantiated for conditions higher than the design point but is detrimental for conditions below the design point. In studying the details of the modeling results (see Appendix) the reason becomes clear. At temperatures and humidities above the design point the indirect evaporative cooler takes on a significant portion of the load that would normally be the job of the vapor compression system. This benefits the system performance as a whole. However, at temperatures and humidities below the design point the portion of the load handled by the indirect evaporative cooler reduces the load on the evaporator and, consequently, the amount of heat that the condenser can contribute to the regeneration of the desiccant dehumidifier. As a result, auxiliary energy makes up the difference, and the overall performance suffers. In general, using the indirect evaporative cooler at temperatures above design point makes sense because of the cooler's ability to aid the vapor compression subsystem. Using a variable effectiveness for the evaporative cooler by bypassing the process air control of the water supplied to the cooler could eliminate this problem. 


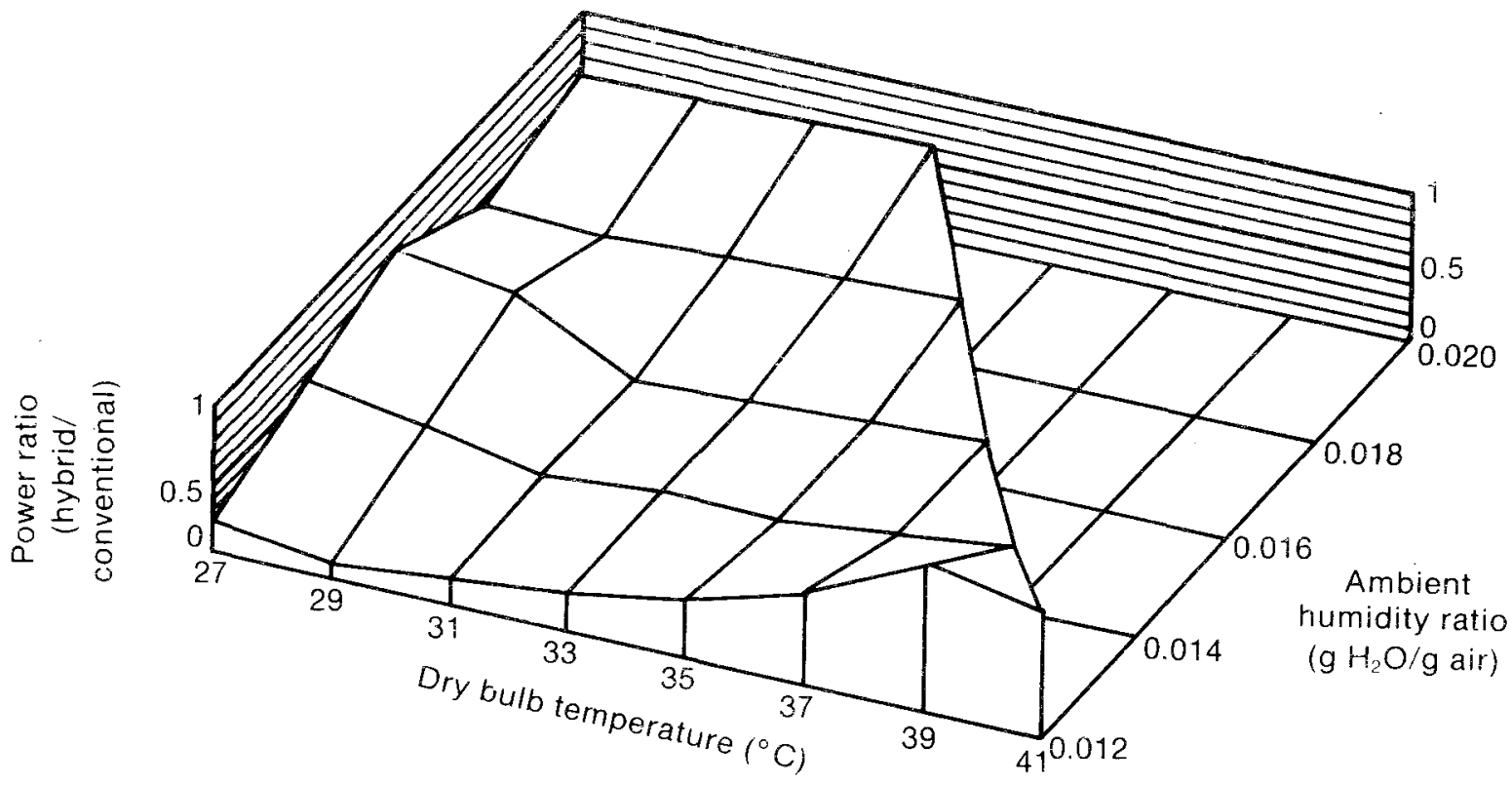

Figure 4-1. Performanee Map of Hybrid System 1 for Varying Outdoor Conditions

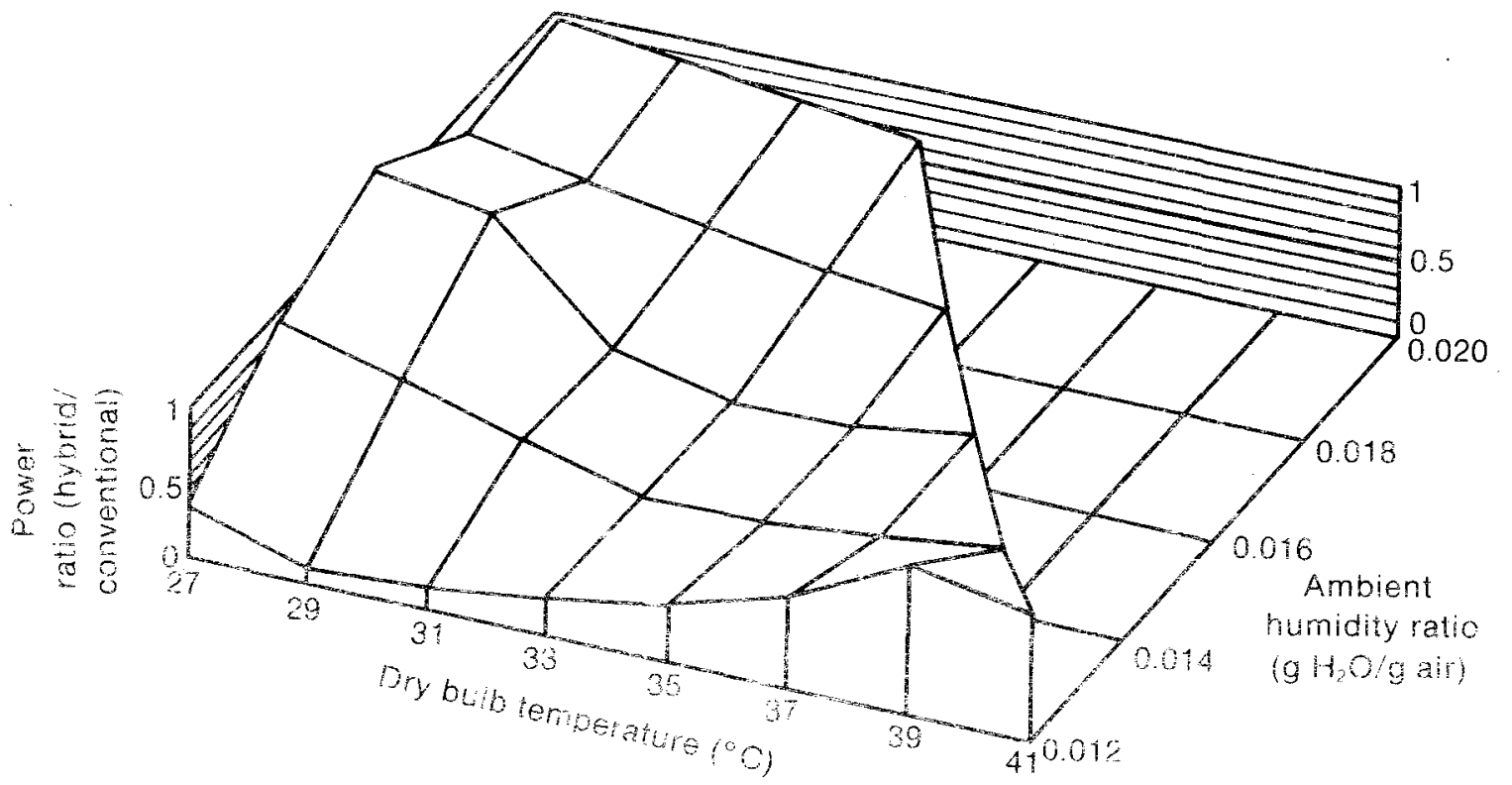

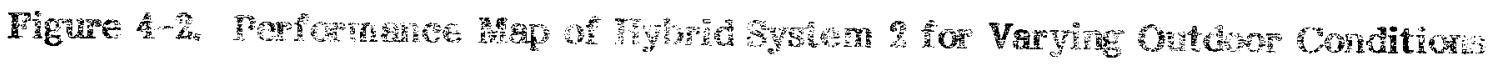




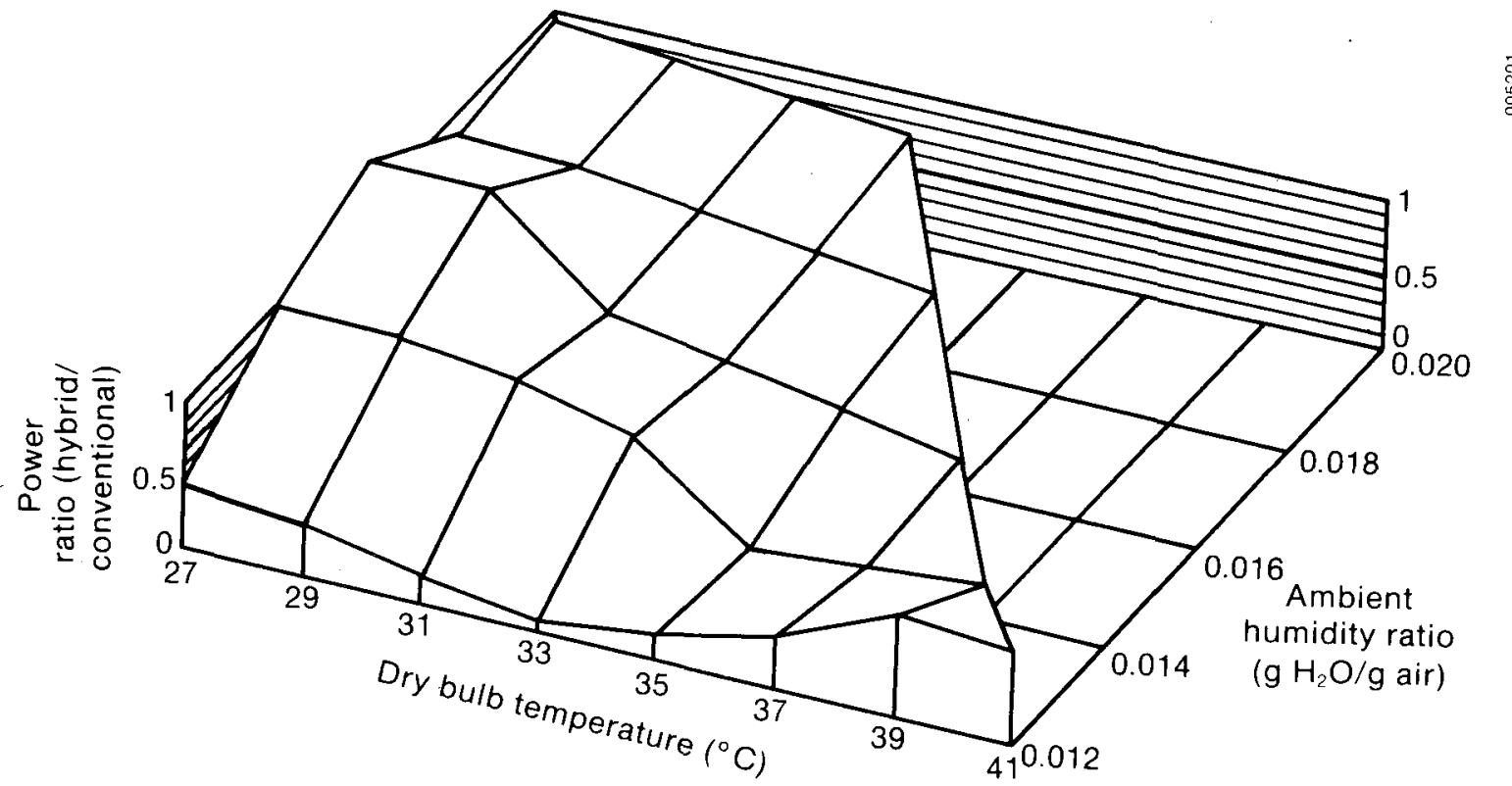

Figure 4-3. Performance Map of Hybrid System 3 for Varying Outdoor Conditions

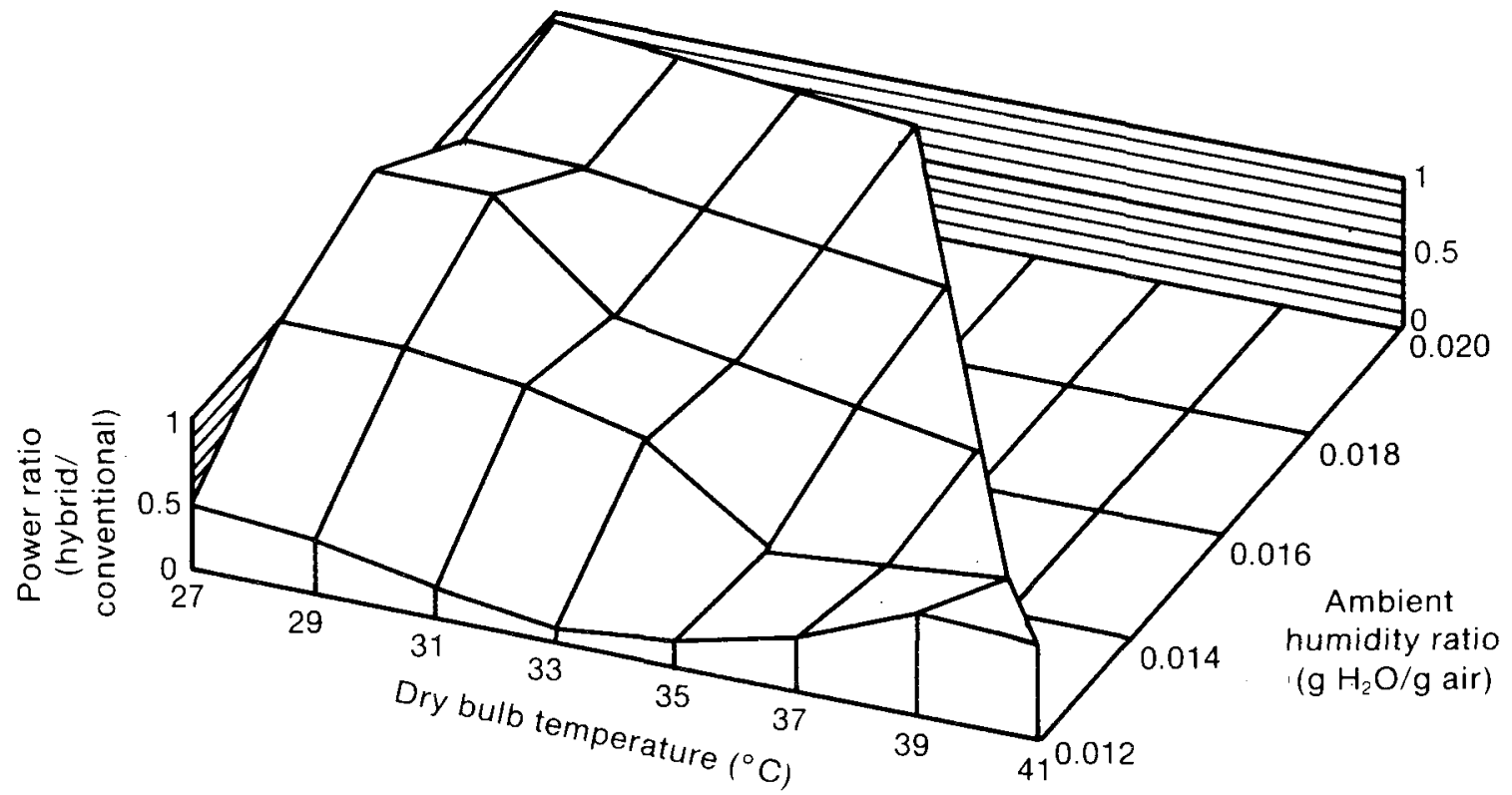

Figure 4-4. Performance Map of Hybrid System 4 for Varying Outdoor Conditions 


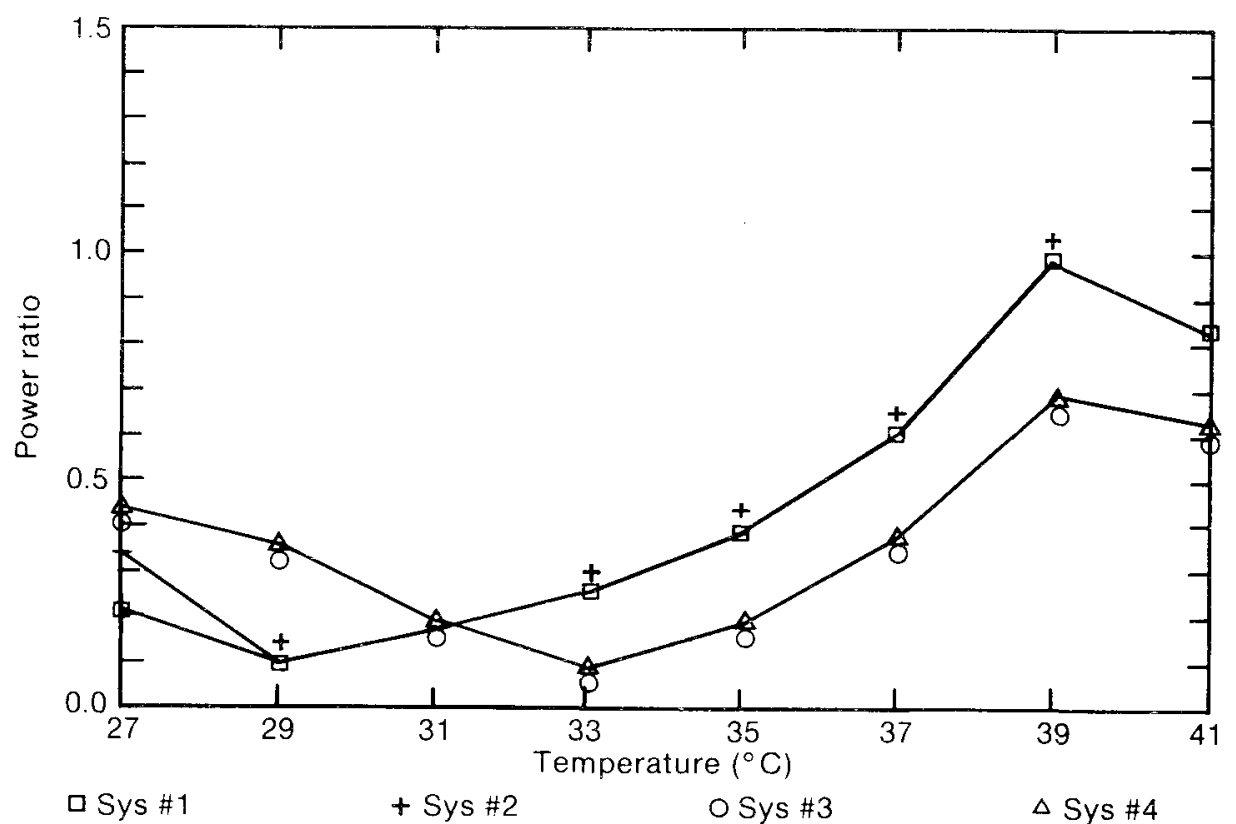

Figure 4-5. System Performance Comparisons at Varying Dry Bulb Temperatures with Humidity Ratio $=0.12 \mathrm{~g} \mathrm{H}_{2} \mathrm{O} / \mathrm{g}$ air

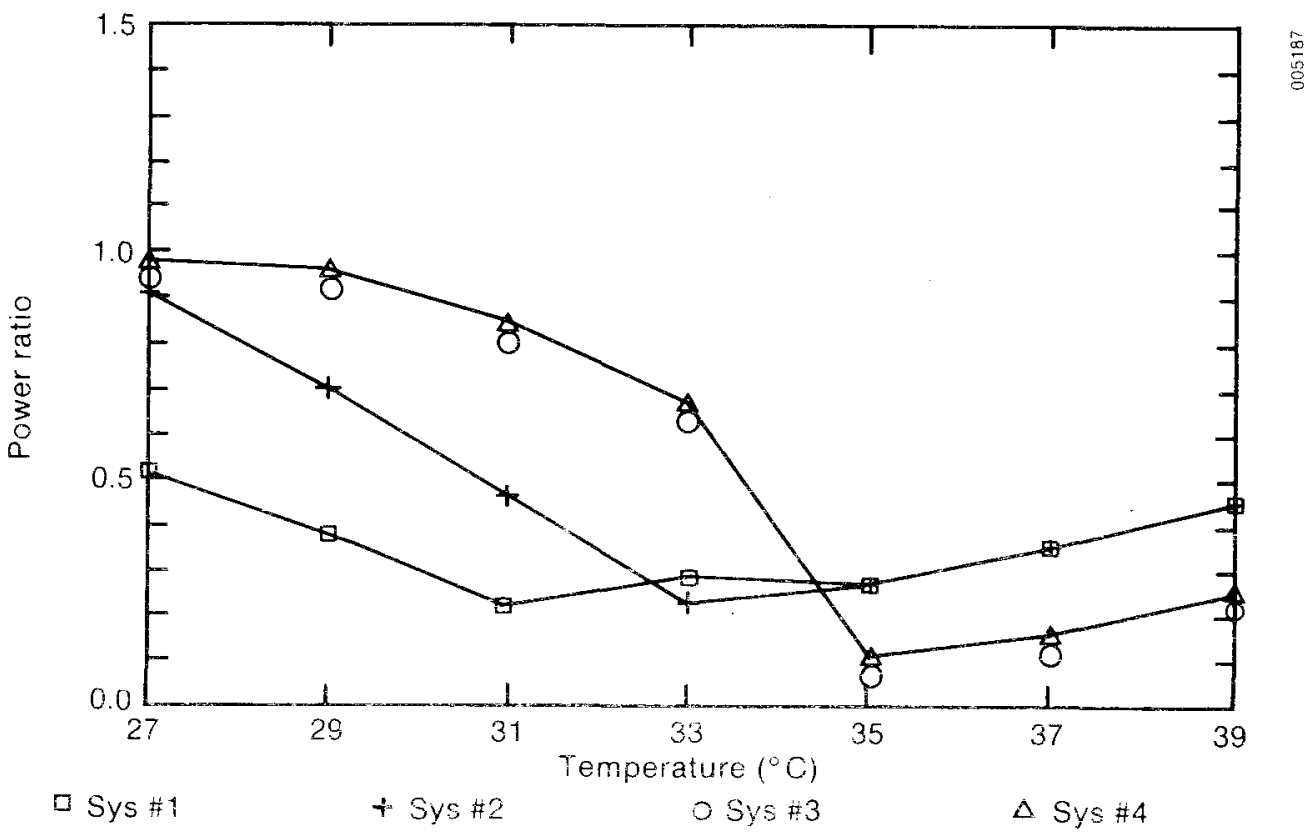

Figure 4-6. System Performanee Comparisons at Vaying Dry Bub Temporatures whin 

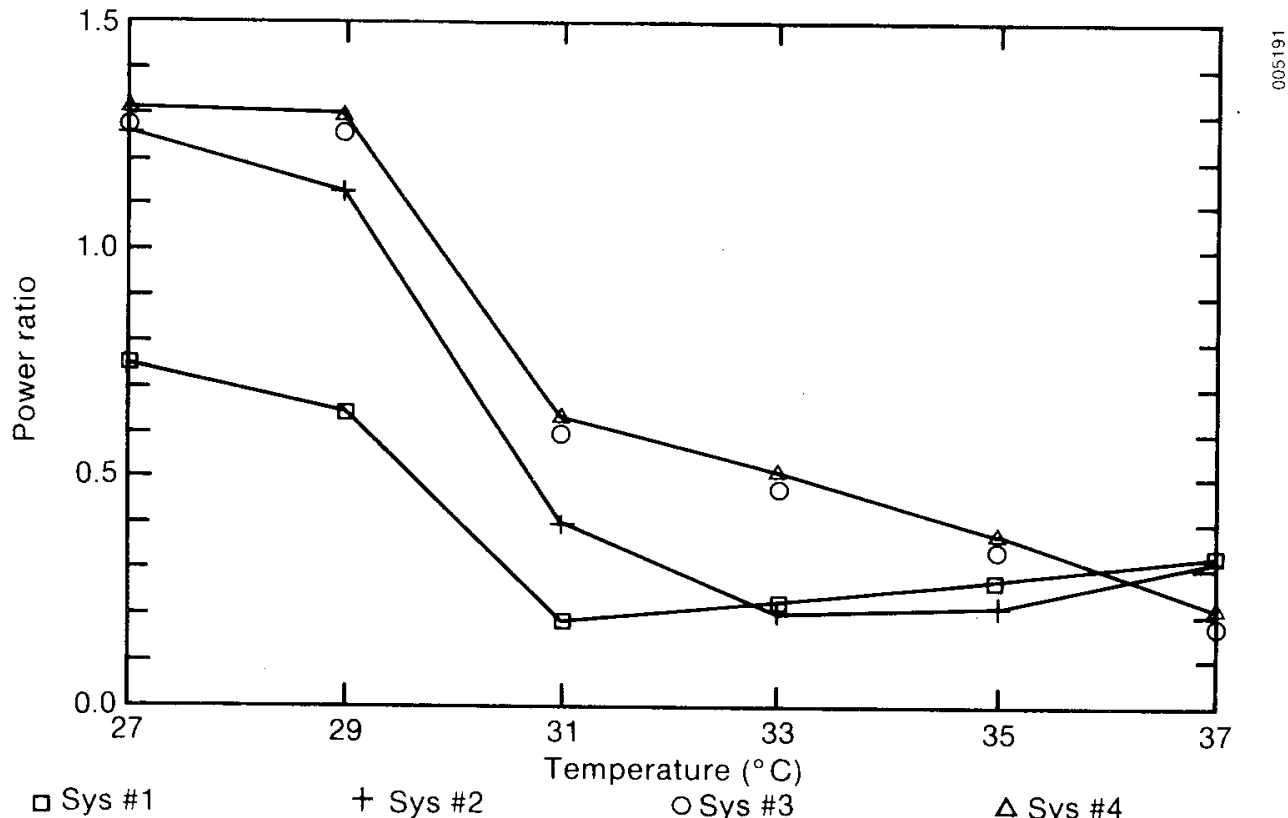
口 Sys \#1
+ Sys \#2
O Sys \#3
$\triangle$ Sys \#4

Figure 4-7. System Performance Comparisons at Varying Dry Bulb Temperatures with Humidity Ratio $=0.16 \mathrm{~g} \mathrm{H}_{2} \mathrm{O} / \mathrm{g}$ air

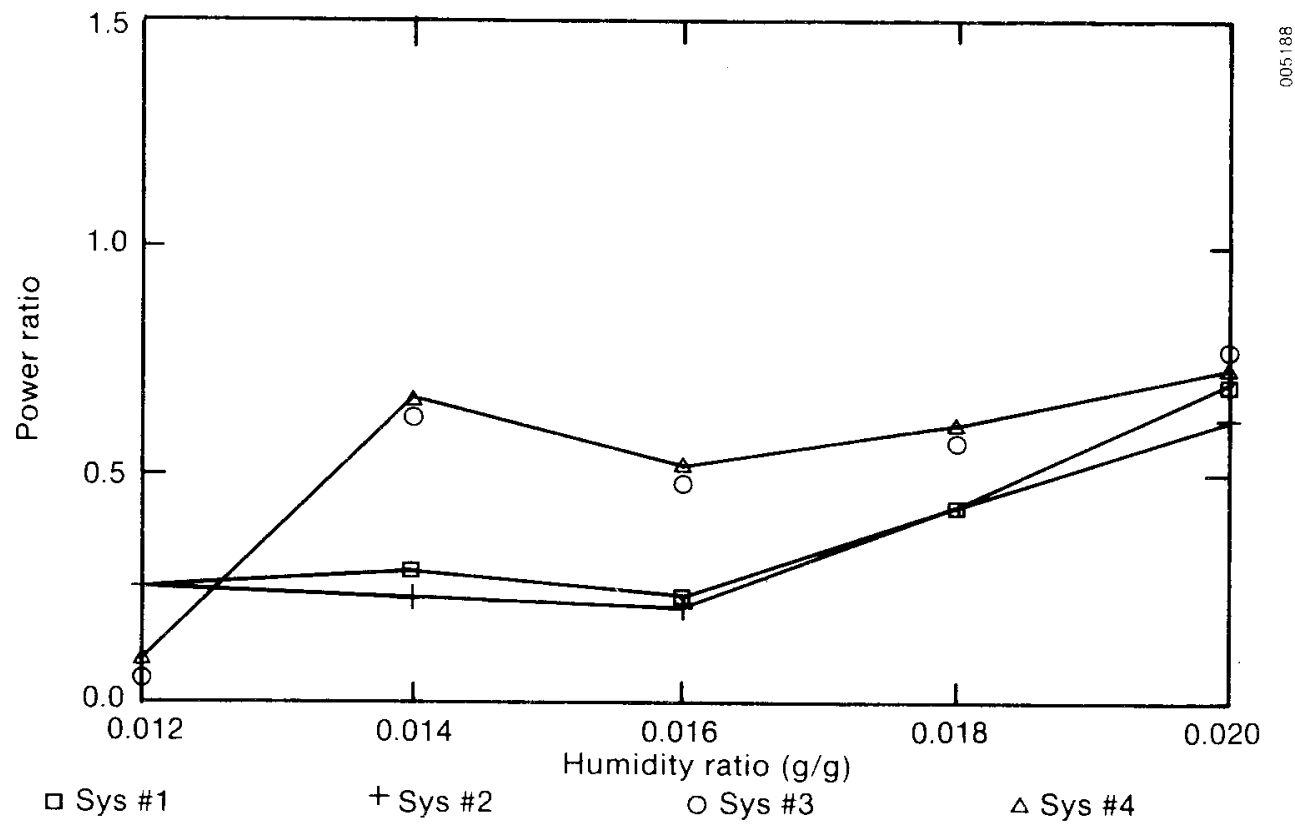

Figure 4-8. System Performance Comparisons with Varying Humidity Ratios at Dry Bulb Temperature $=33^{\circ} \mathrm{C}$ 


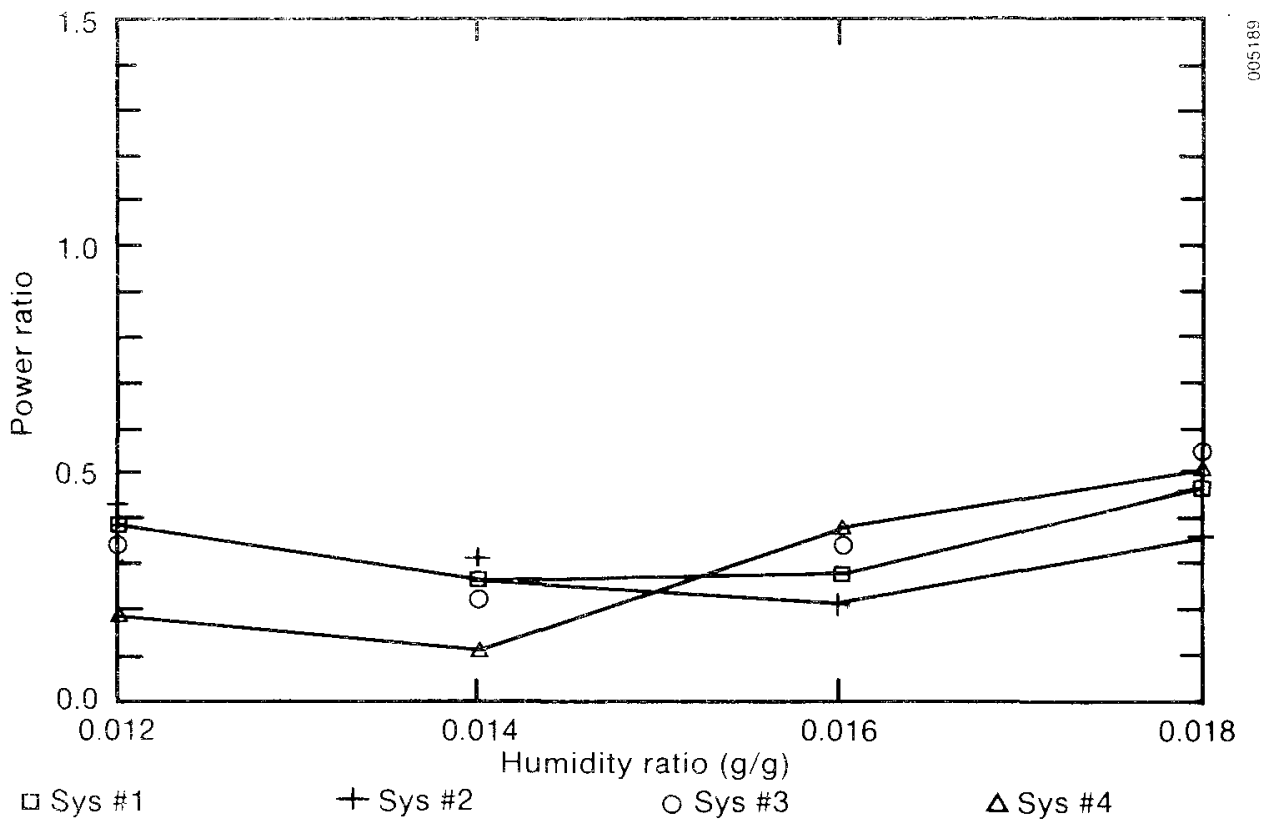

Figure 4-9. System Performance Comparisons with Varying Humidity Ratios at Dry Bulb Temperature $=35^{\circ} \mathrm{C}$

As mentiched earlier, using the heat exchanger had little benefit to the performance of the hyorid system, and, therefore, System 4 has exactly the same performance characteristics as System 3 . The combination of both energy-efficient components is not warranted since all of the increase in performance is gained from the indirect evaporative cooler of System 3.

The key finding of this analysis is that the hybrid system concept can save substantial amounts of resoug ce energy when compared to the conventional system. When properly controlled, the configuration of System 3 wh a variable effectiveness, indirect evaporative cooler conld prove to be a highly efficient air-conditioning system for zll chmates ari loaks. It could use environmental cooling when possible and still provide full baekup th the conventional vapor-compression subsystem. The flexibility and effictercy of such a system are atractive from an operating standpoint. 


\section{SECTION 5.0}

\section{CONCLUSIONS AND RECOMMENDATIONS}

This study shows that a packaged system with hybrid-desiccant/vapor-compression airconditioning can be a technically feasible alternative to conventional air-conditioning systems. Resource energy savings of $30 \%-80 \%$ can be realized over a wide range of operating conditions, when comparing steady-state performance of the hybrid with conventional systems. These results show promise for developing energy-efficient, airconditioning by extending existing state-of-the-art technology and warrant further research and analysis.

Seasonal simulations of the hybrid systems should be undertaken to establish realistic energy savings when operating under variable loads and transient-operating conditions. These system studies should include the simple System 1 studied in this report, where the dehumidifier and vapor-compression subsystems are operated in series, and System 3, which incorporates the indirect evaporative cooler. This analysis must also include development and evaluation of control strategies for operating the various subsystems together.

A laboratory experimental program to verify the analysis of the hybrid concept is required. The effort should involve industrial participation from manufacturers of dehumidifiers and vapor-compression equipment. The project should confirm the accuracy of the design tools used in this study and should measure system performance under actual operating conditions. 


\section{SECTION 6.0}

\section{REFERENCES}

1. Schlepp, D., and K. Schultz, "High Performance Solar Desiccant Cooling Systems: Performance Evaluations and Research Recommendations," SERI/TR-252-2497, Golden, CO: Solar Energy Research Institute, (Dec.) 1983.

2. Cohen, B., A. Levine, and R. Arora, Thermo Electron Corp. "Field Development of a Desiccant-Based Space-Conditioning System for Supermarket Applications," TE4308-42-83, Chicago, IL: Gas Research Institute, (Feb.) 1983.

3. "It's Not the Heat, It's the Humidity," The Energy Daily, Vol. 10, No. 123, 2 July 1982.

4. Sheridan, J., and J. W. Mitchell, "Hybrid Solar Desiccant Cooling Systems," Proceedings of the Annual Meeting of AS/ISES, Houston, TX, 1982.

5. Howe, R. R., W. A. Beckman, and J. W. Mitchell, "Commercial Applications for Solar Hybrid Desiccant Systems," Proceedings of the Annual Meeting of ASES, Minneapolis, MN, 1983.

6. Howe, R. R., W. A. Beckman, and J. W. Mitchell, "Factors Influencing the Performance of Commercial Hybrid Desiccant Air Conditioning Systems," presented at the Intersociety Energy Conversion Engineering Conference, Orlando, FL, (Aug.) 1983.

7. Maclaine-cross, I. L., "A Theory of Combined Heat and Mass Transfer in Regenerators," Ph.D. Thesis, Clayton, Victoria, Australia: Department of Mechanical Engineering, Monash University, 1974.

8. Pescod, D., "Unit Air Cooler Using Plastic Heat Exchanger with Evaporatively Cooled Plates," Australian Refrigeration, Air Conditioning, and Heating, Vol. 22, No. 9, pp. 22-26, 1968 .

9. Schultz, K. L., "The Performance of Desiceant Dehumidifier Air Conditioning Systems Using Cooled Dehumidifiers," M.S. Thesis, Madison: Solar Energy Laboratory, University of Wisconsin, May 1983. 
SERI* 
APPENDIX A

TABULATED STUDY RESULTS 


\section{SEPI}


HYBRID SYSTEM ANALYSIS - SYstem 1

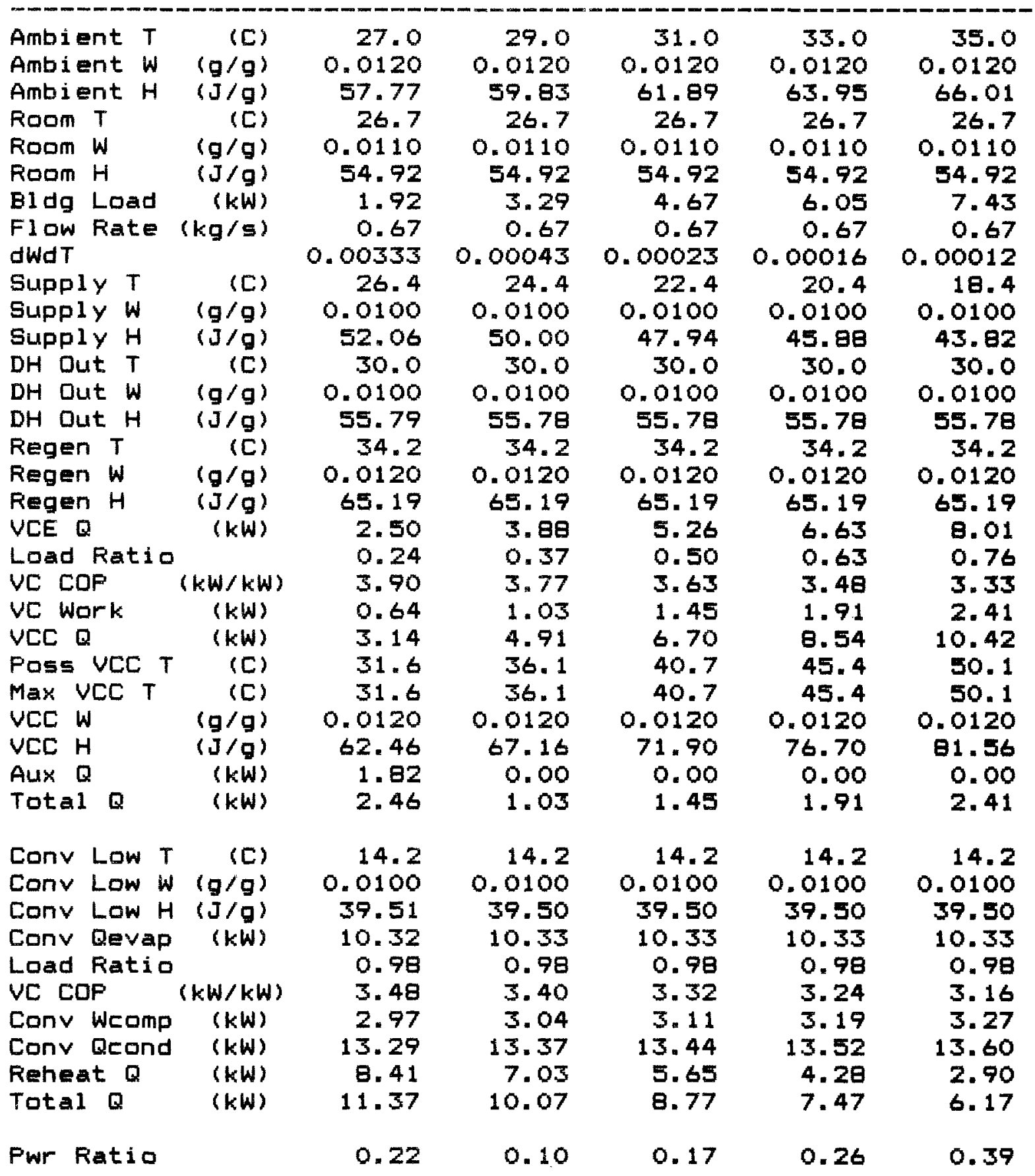




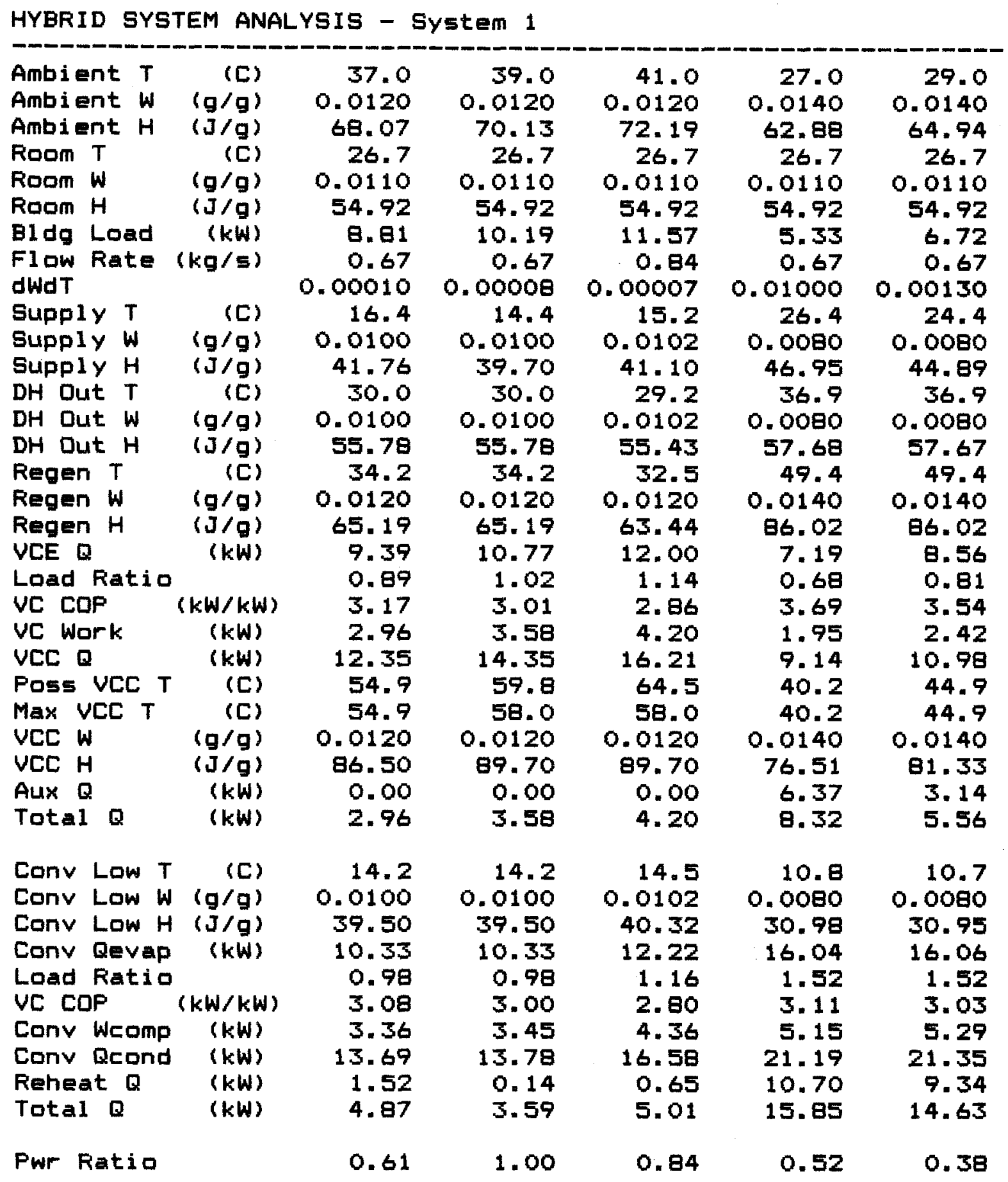


HYBRID SYSTEM ANALYSIS - SYstem 1

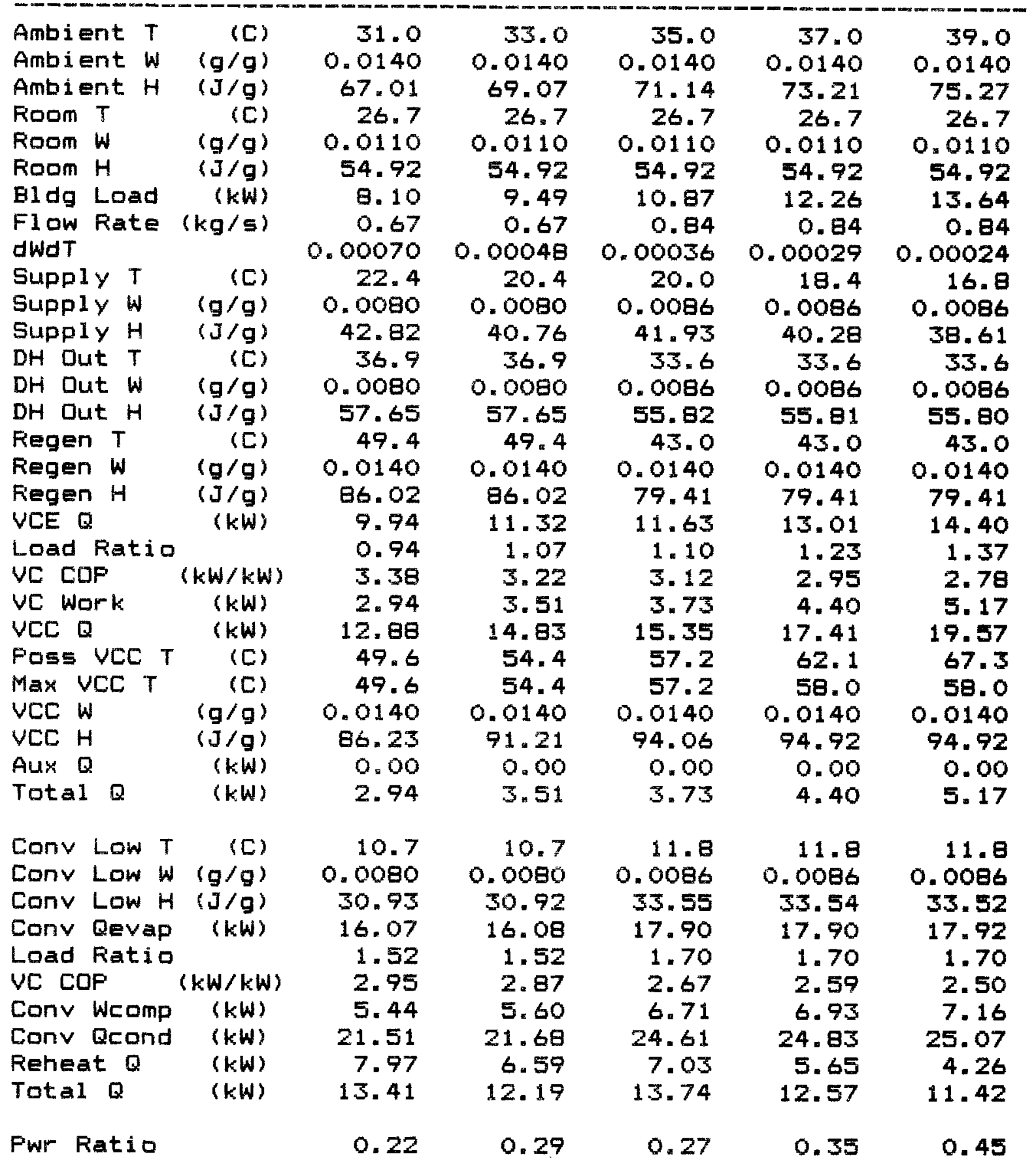




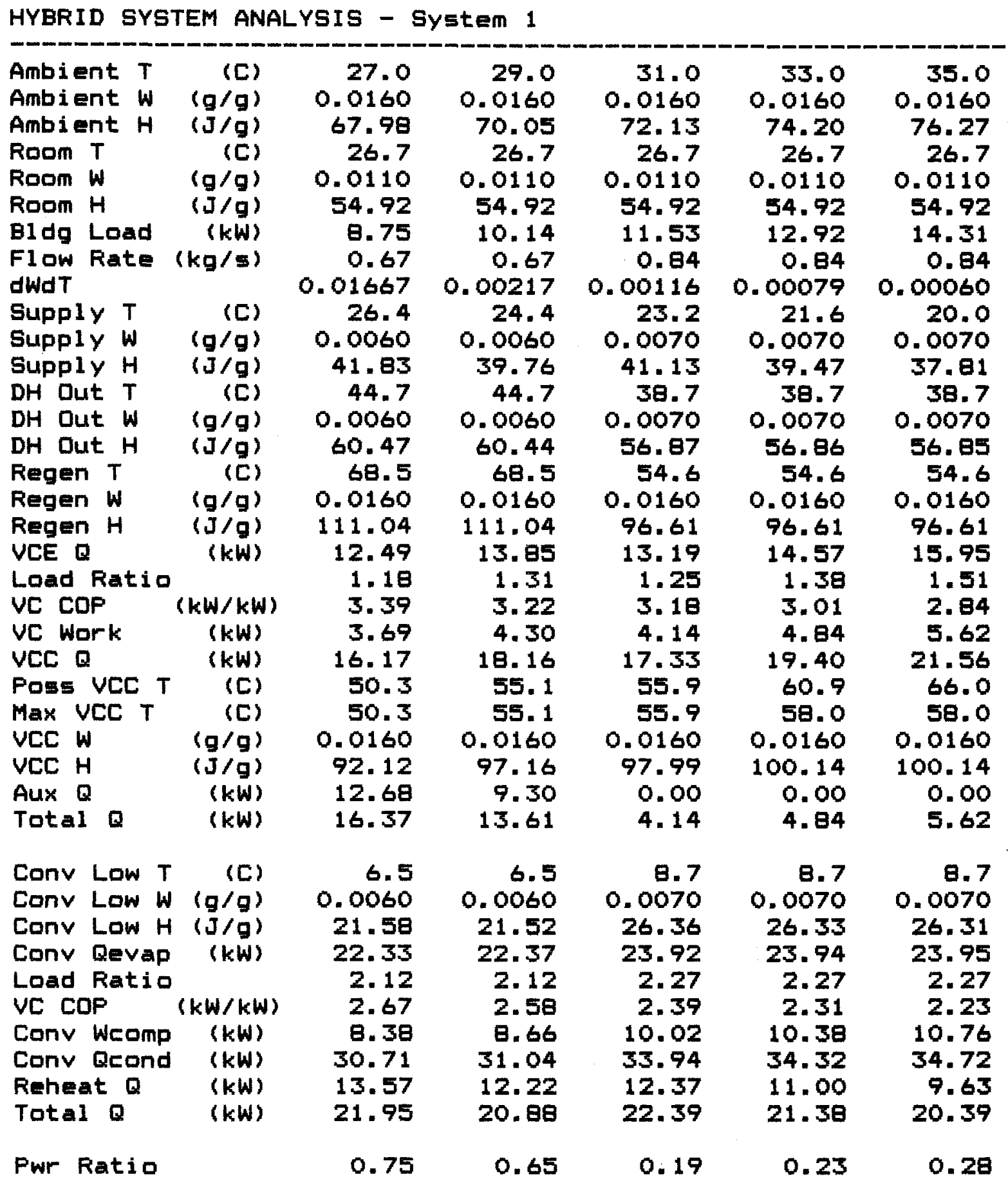


HYERID SYSTEM ANALYSIS - SYStEm 1

\begin{tabular}{|c|c|c|c|c|c|c|}
\hline Ambient $T$ & (C) & 37.0 & 27.0 & 29.0 & 31.0 & 33.0 \\
\hline Ambient w & $(g / g)$ & 0.0160 & 0.0180 & 0.0180 & 0.0180 & 0.0180 \\
\hline Ambient $\mathrm{H}$ & $(\mathrm{J} / 9)$ & 78.35 & 73.08 & 75.16 & 77.24 & 79.32 \\
\hline Foom $T$ & $(\tilde{C})$ & 26.7 & 26.7 & 26.7 & 26.7 & 26.7 \\
\hline Room $W$ & $(g / g)$ & 0.0110 & 0.0110 & 0.0110 & 0.0110 & 0.0110 \\
\hline Room $H$ & $(J / g)$ & 54.92 & 54.92 & 54.92 & 54.92 & 54.92 \\
\hline BIdg Load & (kw) & 15.70 & 12.17 & 13.57 & 14.96 & 16.35 \\
\hline Flow Rate & $(\mathrm{kg} / \mathrm{s})$ & 0.04 & 0.84 & 0.94 & 0.84 & 0.84 \\
\hline dWdT & & 0.00049 & 0.02533 & 0.00304 & 0.00163 & 0.00111 \\
\hline Supply T & (c) & 18.4 & 26.5 & 24.9 & 23.2 & 21.6 \\
\hline Supply w & $\lg / g)$ & 0.0070 & 0.0054 & 0.0054 & 0.0054 & 0.0054 \\
\hline Supply & $(J / g)$ & 36.15 & 40.36 & 38.70 & 37.03 & 35.37 \\
\hline DH out $T$ & (E) & 38.7 & 43.5 & 43.9 & 43.9 & 43.9 \\
\hline DH Dut W & $(g / g)$ & 0.0070 & 0.0054 & 0.0054 & 0.0054 & 0.0054 \\
\hline DH Out $H$ & $(\vec{J} / g)$ & 56.84 & 58.10 & $5 \mathrm{~B} .07$ & 58.04 & 58.02 \\
\hline Regen $T$ & $(C)$ & 54.6 & 67.5 & 67.5 & 67.5 & 67.5 \\
\hline Regen $w$ & $(g / g)$ & 0.0160 & 0.0180 & 0.0180 & 0.0180 & 0.0180 \\
\hline Regen $H$ & $(J / g)$ & 96.61 & 115.26 & 115.26 & 115.26 & 115.26 \\
\hline VCE Q & (kw) & 17.33 & 14.86 & 16.22 & 17.60 & 18.97 \\
\hline Load Fatio & & 1.64 & 1.41 & 1.54 & 1.67 & 1.80 \\
\hline VC $\mathrm{COP}$ & $(\mathrm{kW} / \mathrm{kW})$ & 2.67 & 3.23 & 3.06 & 2.89 & 2.71 \\
\hline VC Work & $(f, W)$ & 6.50 & 4.59 & 5.30 & 6.10 & 7.00 \\
\hline VCC 0 & $(\mathrm{~kW})$ & 23.83 & 19.45 & 21.52 & 23.69 & 25.98 \\
\hline Poss VeC T & (C) & 71.3 & 54.9 & 59.7 & 65.0 & 70.2 \\
\hline $\operatorname{Max}$ VCC $T$ & (C) & 58.0 & 54.9 & 58.0 & 58.0 & 58.0 \\
\hline VCC $w$ & $(g / g)$ & 0.0160 & 0.0180 & 0.0180 & 0.0180 & 0.0180 \\
\hline VCE $H$ & $(\mathrm{~J} / \mathrm{g})$ & 100.14 & 102.11 & 105.36 & 105.36 & 105.36 \\
\hline Aux Q & (kw) & 0.00 & 8.80 & 6.63 & 6.63 & 6.63 \\
\hline Total Q & $(k W)$ & 6.50 & 13.40 & 11.93 & 12.73 & 13.64 \\
\hline Conv Low $T$ & (C) & 8.7 & 4.9 & 4.8 & 4.8 & 4.8 \\
\hline Coriv Low W & $(g / g)$ & 0.0070 & 0.0054 & 0.0054 & 0.0054 & 0.0054 \\
\hline Conv Low $H$ & $(\mathrm{~J} / \mathrm{g})$ & 26.30 & 18.41 & 18.34 & 18.29 & 18.24 \\
\hline Conv Qevap & (kw) & 23.97 & 30.57 & 30.63 & 30.68 & 30.72 \\
\hline Load Ratio & & 2.27 & 2.90 & 2.90 & 2.91 & 2.91 \\
\hline VC COF & $(\mathrm{kW} / \mathrm{kW})$ & 2.14 & 2.04 & 1.96 & 1.87 & 1.79 \\
\hline Conv Wcomp & $(k w)$ & 11,18 & 14.97 & 15.64 & 16.37 & 17.15 \\
\hline Conv Qcond & $(k \omega)$ & 35.14 & 45.54 & 46.27 & 47.04 & 47.86 \\
\hline Reheat Q & (kw) & 8.25 & 18.39 & 17.05 & 15.70 & 14.35 \\
\hline Total Q & $(k W)$ & 19.43 & 33.36 & 32.69 & 32.07 & 31.49 \\
\hline Pwr Ratio & & 0.33 & 0.40 & 0.37 & 0.40 & 0.43 \\
\hline
\end{tabular}


HYBRID SYSTEM ANALYSIS - SYstem 1

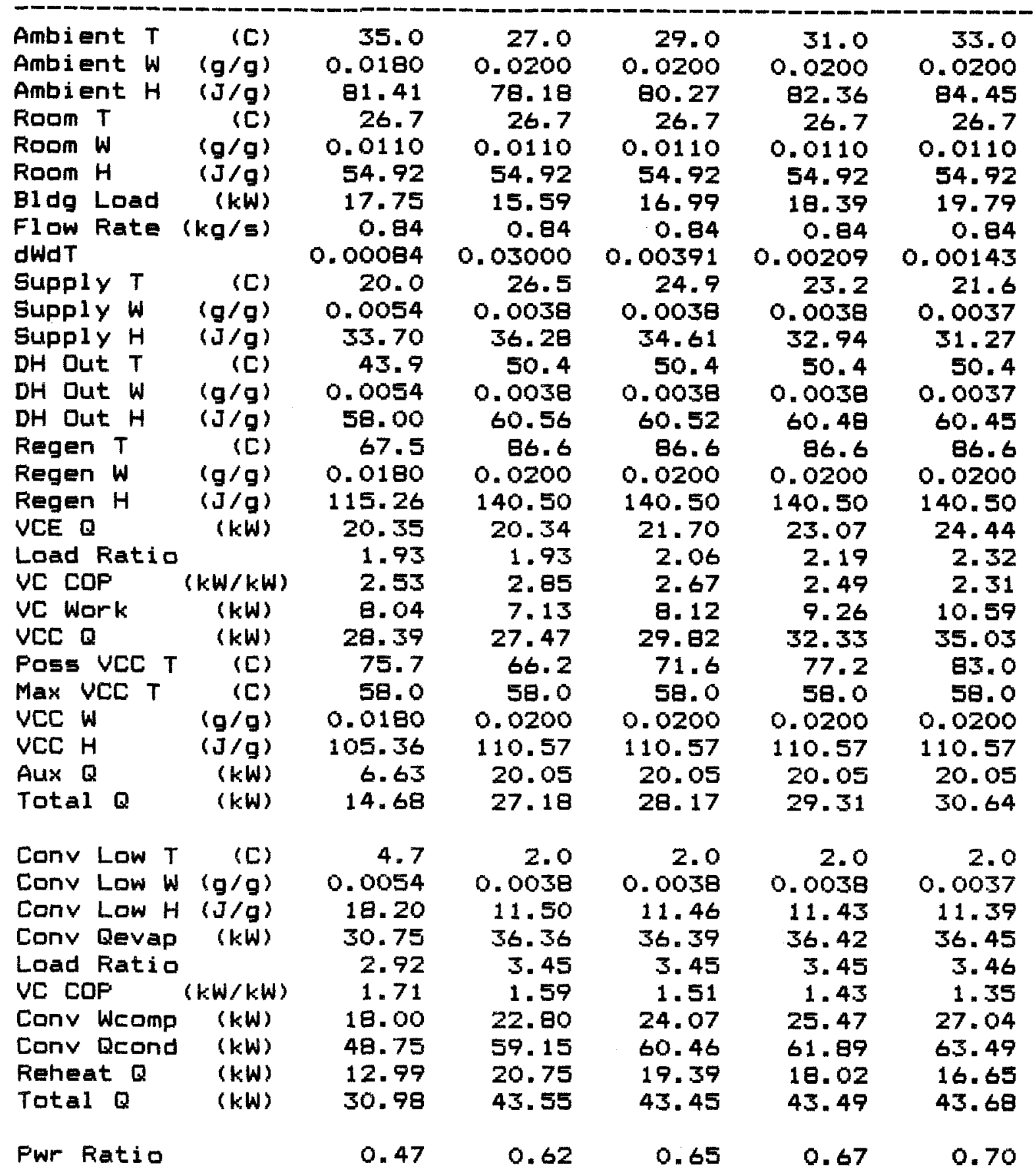


HYERID SYSTEM ANNALYSIS - SYStEm 2

\begin{tabular}{|c|c|c|c|c|c|c|}
\hline Ambient $T$ & (C) & 27.0 & 29.0 & 31.0 & 33.0 & 35.0 \\
\hline Ambient $w$ & $(g / g)$ & 0.0120 & 0.0120 & 0.0120 & 0.0120 & 0.0120 \\
\hline Ambient $H$ & $(j / g)$ & 57.77 & 59.83 & 61.89 & 63.95 & 66.01 \\
\hline Room $T$ & (C) & 26.7 & 26.7 & 26.7 & 26.7 & 26.7 \\
\hline Room $W$ & $(g / g)$ & 0.0110 & 0.0110 & 0.0110 & 0.0110 & 0.0110 \\
\hline Room $H$ & $(\mathrm{~J} / \mathrm{g})$ & 54.92 & 54.92 & 54.92 & 54.92 & 54.92 \\
\hline B1 dg Load & $(k W)$ & 1.92 & 3.29 & 4.67 & 6.05 & 7.43 \\
\hline Flow Rate & $(\mathrm{kg} / \mathrm{s})$ & 0.67 & 0.67 & 0.67 & 0.67 & 0.67 \\
\hline dWdT & & 0.00333 & 0.00043 & 0.00023 & 0.00016 & 0.00012 \\
\hline Supply $T$ & (C) & 26.4 & 24.4 & 22.4 & 20.4 & 18.4 \\
\hline Supply w & $(g / g)$ & 0.0100 & 0.0100 & 0.0100 & 0.0100 & 0.0100 \\
\hline Supply H & $(J / g)$ & 52.06 & 50.00 & 47.94 & 45.88 & 43.82 \\
\hline DH Dut $T$ & (C) & 30.0 & 30.0 & 30.0 & 30.0 & 30.0 \\
\hline DH qut $w$ & $(g / g)$ & 0.0100 & 0.0100 & 0.0100 & 0.0100 & 0.0100 \\
\hline DH Dut $H$ & $(\vec{J} / g)$ & 55.79 & 55.78 & 55.78 & 55.78 & 55.78 \\
\hline$H X$ Lo $T$ & (C) & 28.0 & 30.0 & 30.0 & 30.0 & 30.0 \\
\hline HX LO W & $(g / g)$ & 0.0100 & 0.0100 & 0.0100 & 0.0100 & 0.0100 \\
\hline$H X$ LO $H$ & $(J / g)$ & 53.70 & 55.74 & 55.78 & 55.78 & 55.78 \\
\hline Regen $T$ & (C) & 34.2 & 34.2 & 34.2 & 34.2 & 34.2 \\
\hline Regen $W$ & $(g / g)$ & 0.0120 & 0.0120 & 0.0120 & 0.0120 & 0.0120 \\
\hline Regen $\mathrm{H}$ & $(J / g)$ & 65.19 & 65.19 & 65.19 & 65.19 & 65.19 \\
\hline$H X H i T$ & (E) & 29.0 & 29.0 & 31.0 & 33.0 & 35.0 \\
\hline $\mathrm{HX} \mathrm{Hi} \mathrm{W}$ & $(g / g)$ & 0.0120 & 0.0120 & 0.0120 & 0.0120 & 0.0120 \\
\hline $\mathrm{HX} \mathrm{Hi} \mathrm{H}$ & $(j / g)$ & 59.87 & 59.87 & 61.89 & 63.75 & 66.01 \\
\hline VCE $\mathrm{Q}$ & $(k \bar{W})$ & 1.10 & 3.85 & 5.26 & 6.63 & B. 01 \\
\hline Load Ratic & & 0.10 & 0.36 & 0.50 & 0.63 & 0.76 \\
\hline YC COP & $(k w / k w)$ & 3.95 & 3.77 & 3.63 & $3.4 \mathrm{~B}$ & 3.33 \\
\hline ve Work & $(k w)$ & 0.28 & 1.02 & 1.45 & 1.91 & 2.41 \\
\hline VCC Q & $(\mathrm{kW})$ & 1.38 & 4.87 & 6.70 & B. 54 & 10.42 \\
\hline Poss VCC $T$ & (C) & 29.0 & 36.1 & 40.7 & 45.4 & 50.1 \\
\hline Max VCC $T$ & (C) & 29.0 & 36.1 & 40.7 & 45.4 & 50.1 \\
\hline VCE $w$ & $(g / g)$ & 0.0120 & 0.0120 & 0.0120 & 0.0120 & 0.0120 \\
\hline VCE $H$ & $(j / g)$ & 59.83 & 67.10 & 71.90 & 76.70 & 81.56 \\
\hline Aux Q & $(k W)$ & 3.59 & 0.00 & 0.00 & 0.00 & 0.00 \\
\hline Total Q & $(\mathrm{kW})$ & 3.87 & 1.02 & 1.45 & 1.91 & 2.41 \\
\hline Conv Low $T$ & (C) & 14.2 & 14.2 & 14.2 & 14.2 & 14.2 \\
\hline Conv Low $h$ & $(g / g)$ & 0.0100 & 0.0100 & 0.0100 & 0.0100 & 0.0100 \\
\hline Conv Low 1 & $(\mathrm{~J} / g)$ & 39.51 & 39.50 & 39.50 & 39.50 & 39.50 \\
\hline Conv Qevap & (kw) & 10.32 & 10.33 & 10.33 & 10.33 & 10.33 \\
\hline Load Ratic & & 0.98 & 0.78 & 0.78 & 0.98 & 0.98 \\
\hline VC COF & $(\mathrm{kW} / \mathrm{kW})$ & 3.48 & 3.40 & 3.32 & 3.24 & 3.16 \\
\hline Conv Weomf & $(k W)$ & 2.97 & 3.04 & 3.11 & 3.19 & 3.27 \\
\hline Conv deond & $(k W)$ & 13.29 & 13.37 & 13.44 & 13.52 & 13.60 \\
\hline Ferieat 0 & $\langle k \mid w\rangle$ & 9.41 & 7.0 .5 & 5.65 & 4.28 & 2.90 \\
\hline Total Q & $(k w)$ & 11.37 & 10.07 & 8.77 & 7.47 & 6.17 \\
\hline Pwr Ratio & & 0.34 & 0.10 & 0.17 & 0.26 & 0.39 \\
\hline
\end{tabular}


HYBRID SYSTEM ANALYSIS - SYStem 2

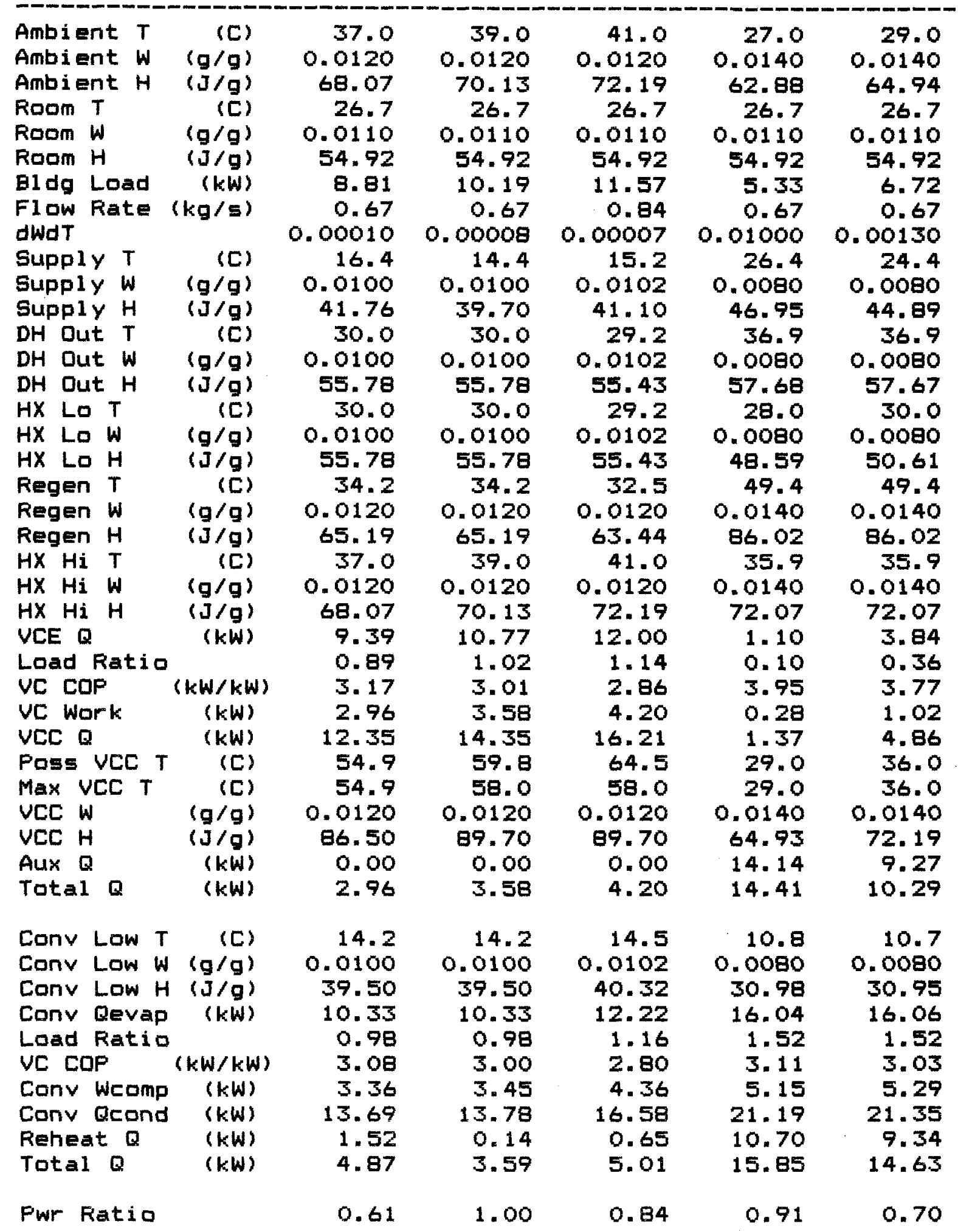


HYBRID SYSTEM ANALYSIS - SYStem 2

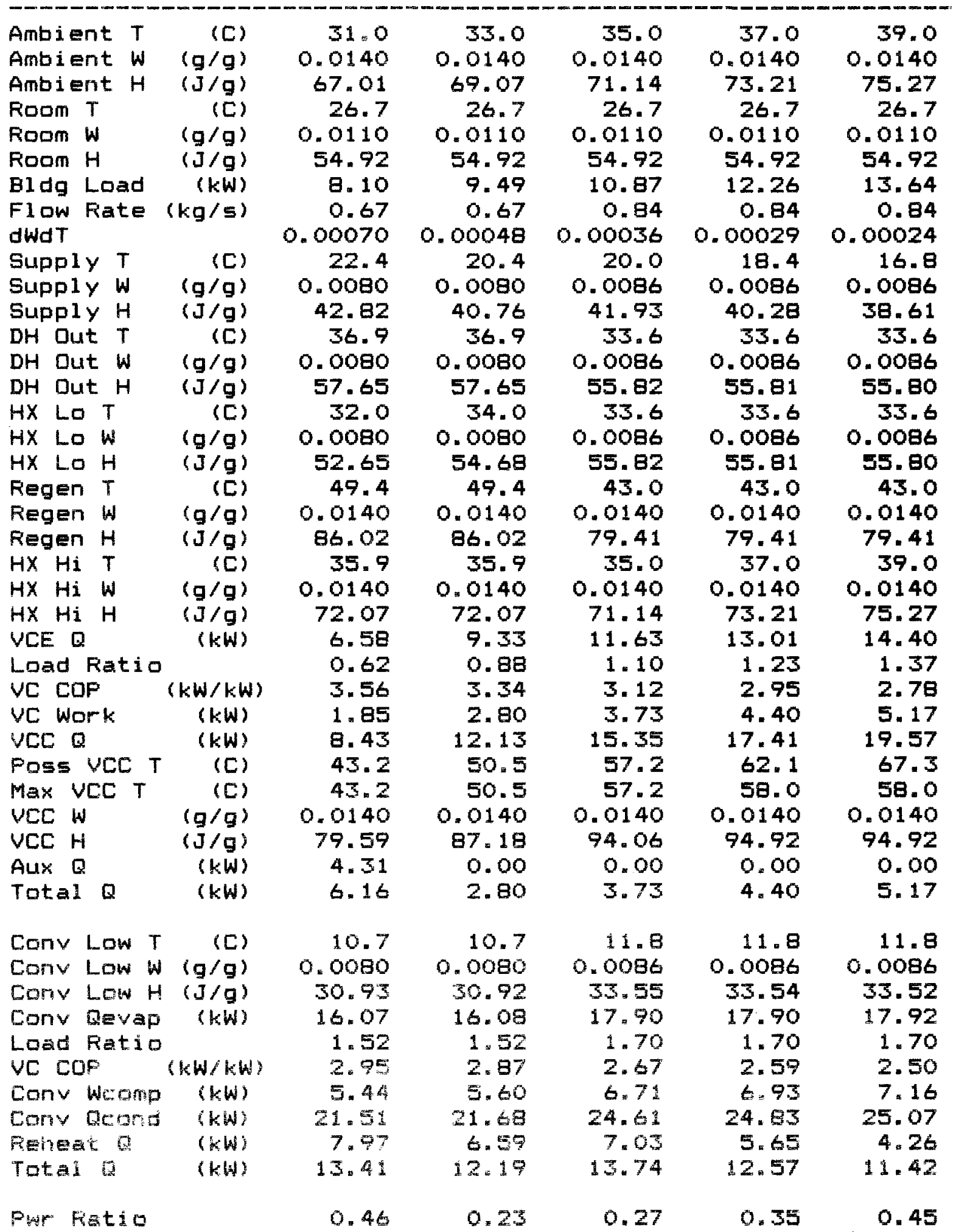


HYBRID SYSTEM ANALYSIS - System 2

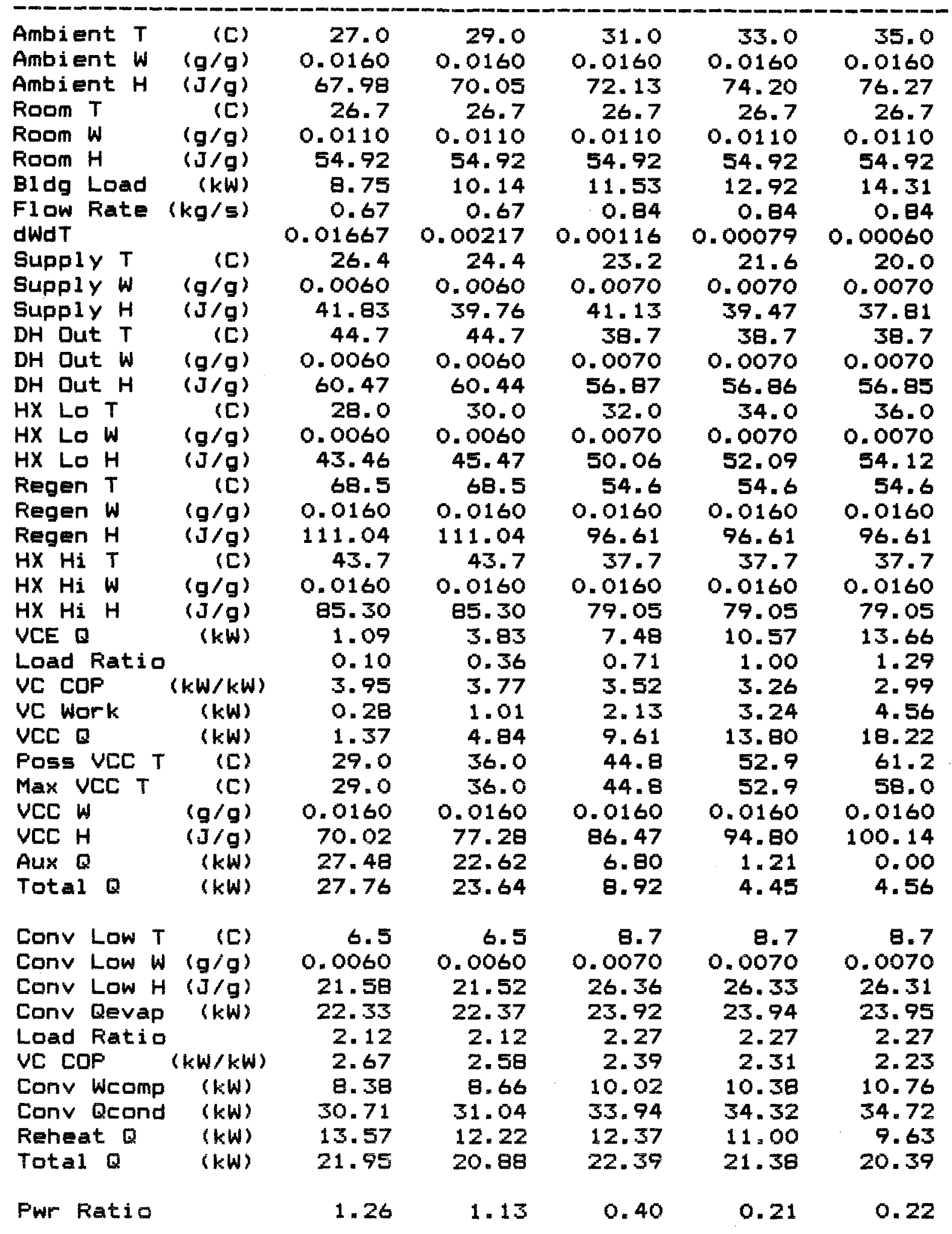


HYBRID SYSTEM ANALYSIS - SYStEm 2

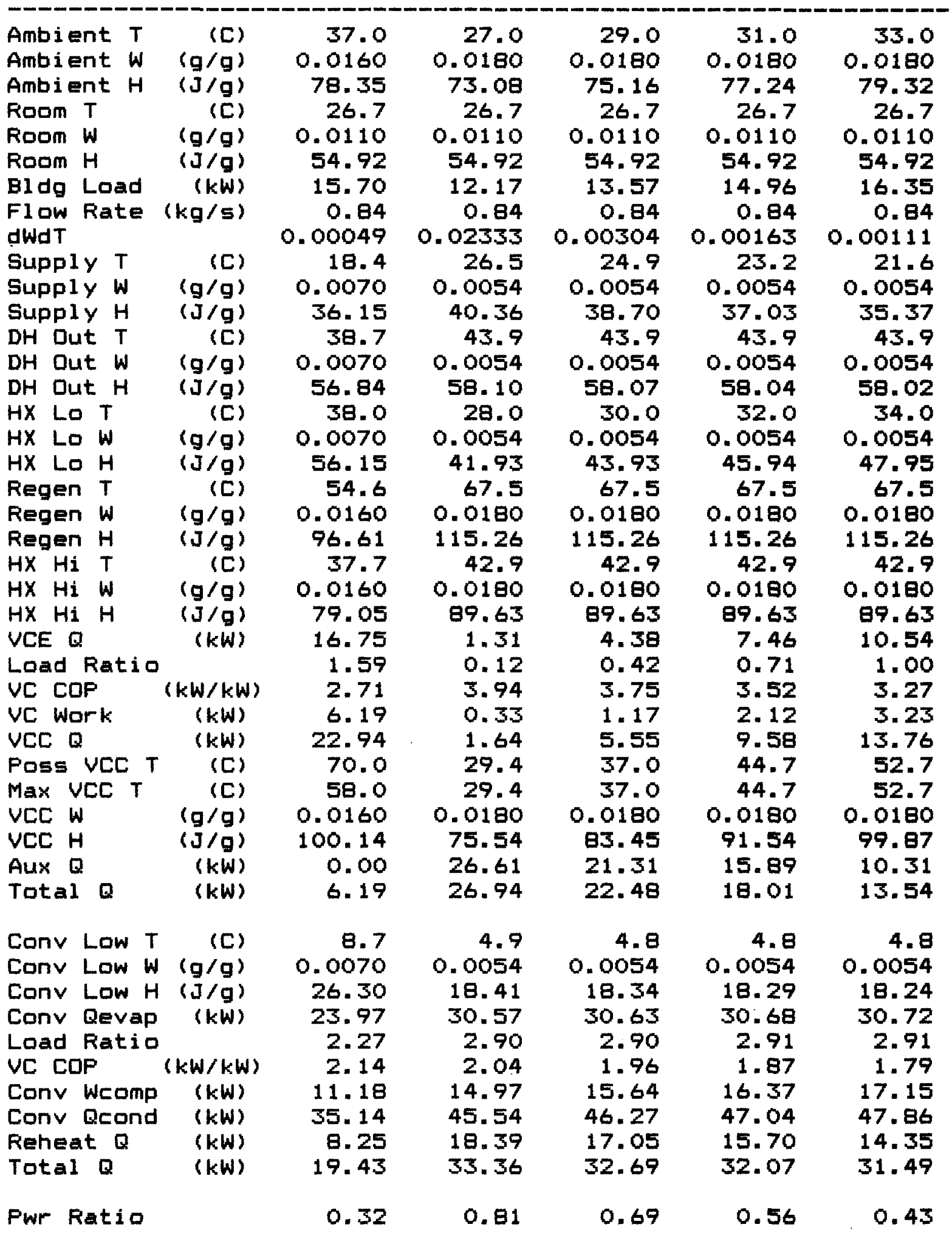


HYBRID SYSTEM ANALYSIS - SYstEm 2

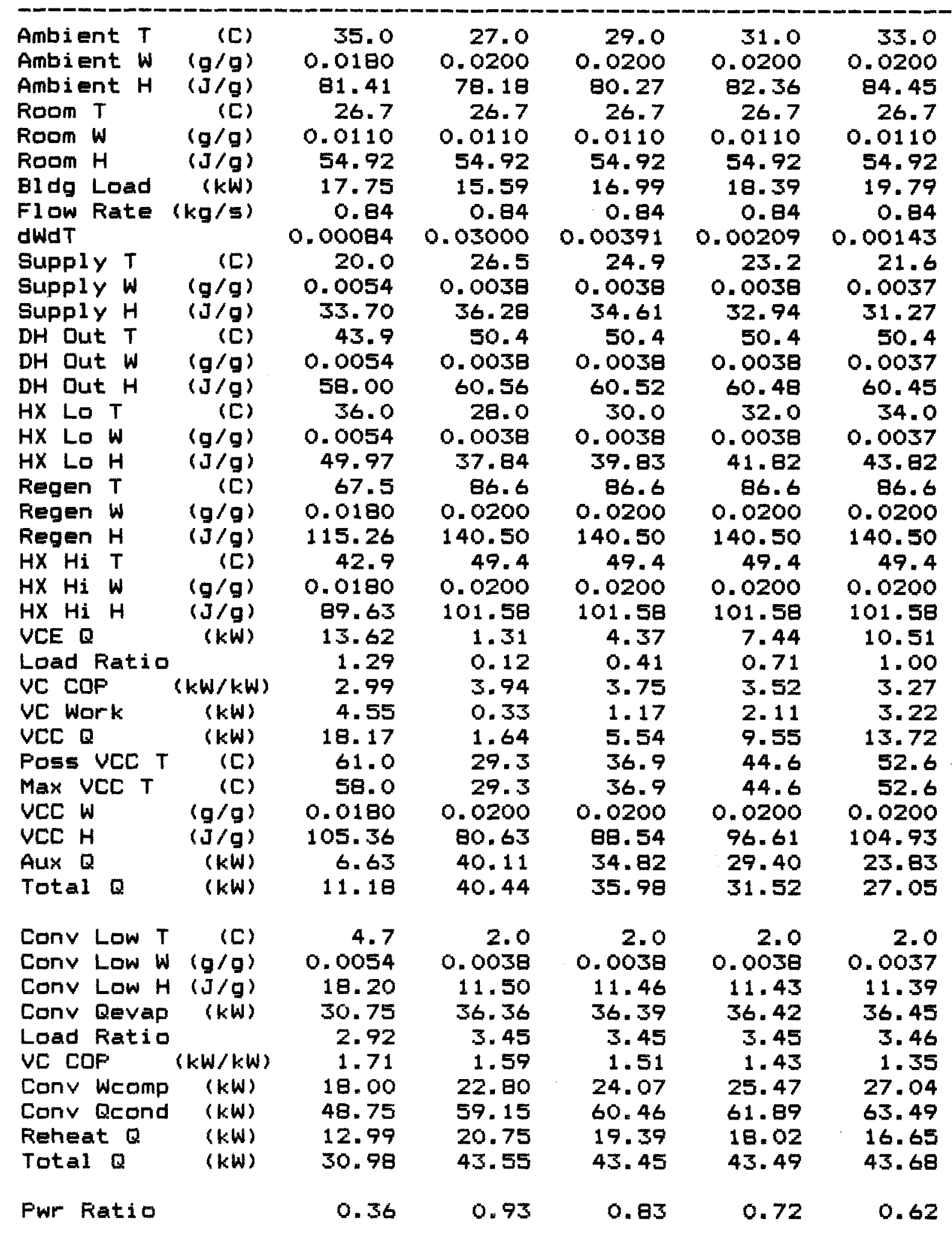


HYBRID SYSTEM ANALYSIS - SYstem 3

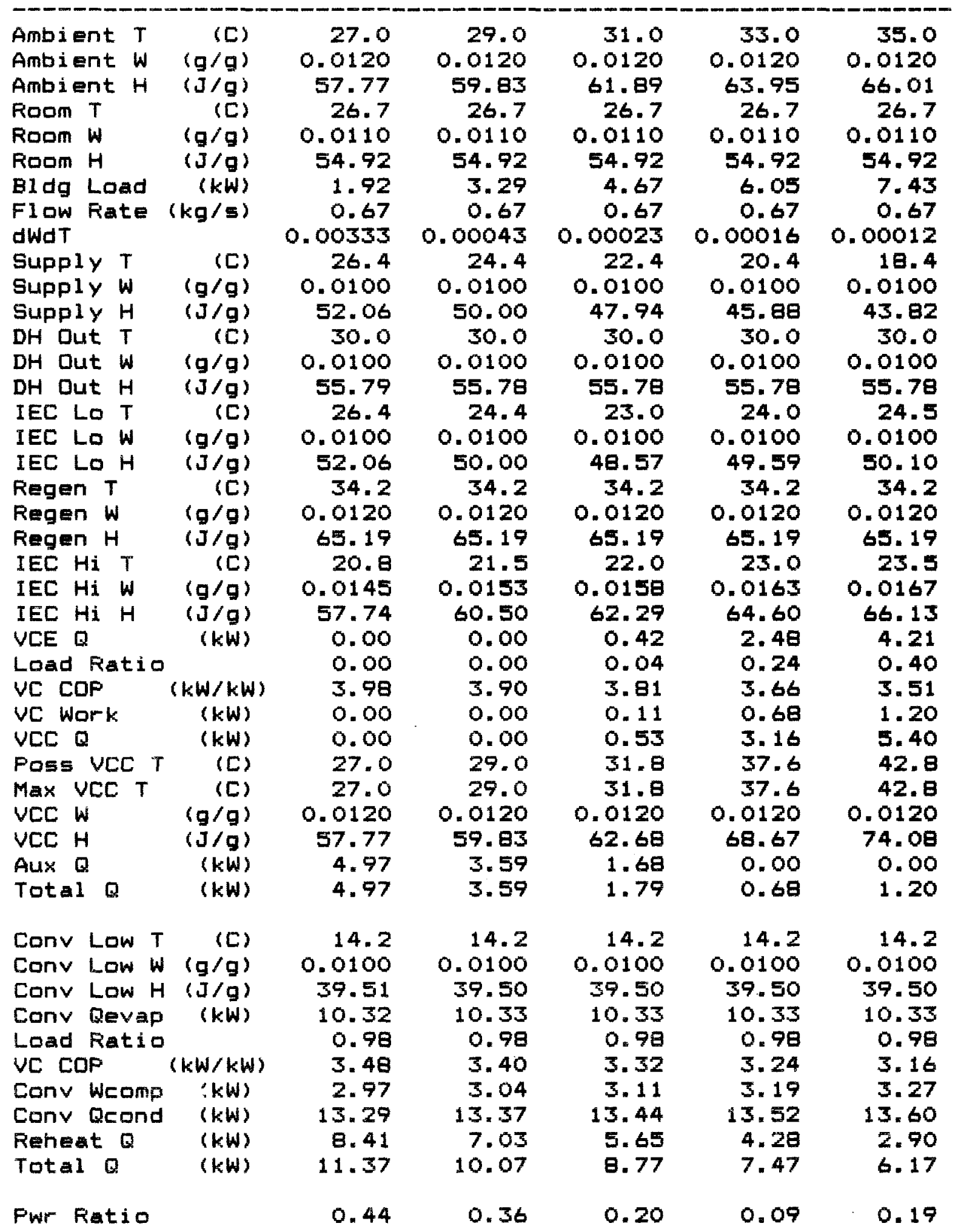


HYBRID SYSTEM ANALYSIS - System 3

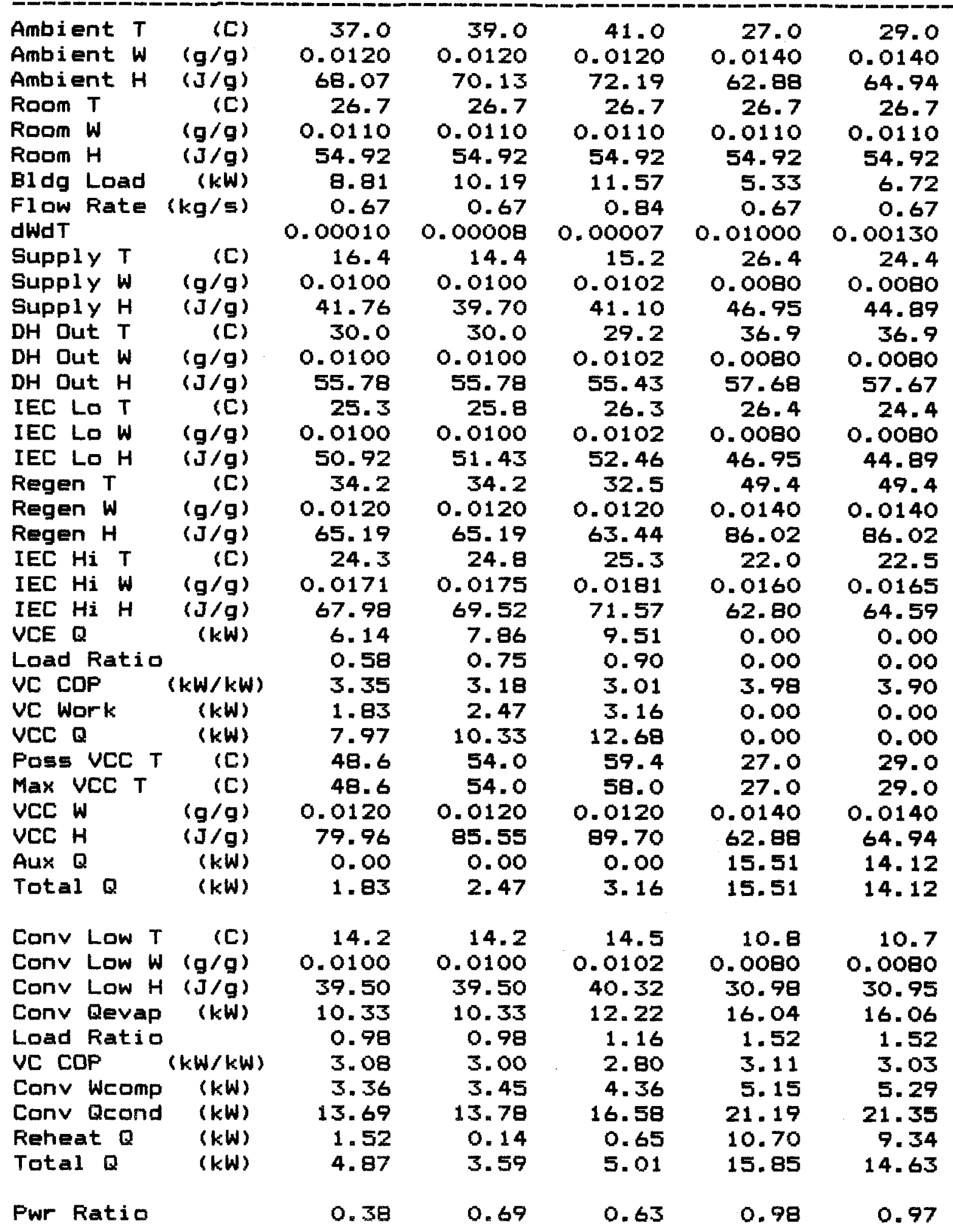


MYOKID SYSTEM ANALYSIS - SYstem 3

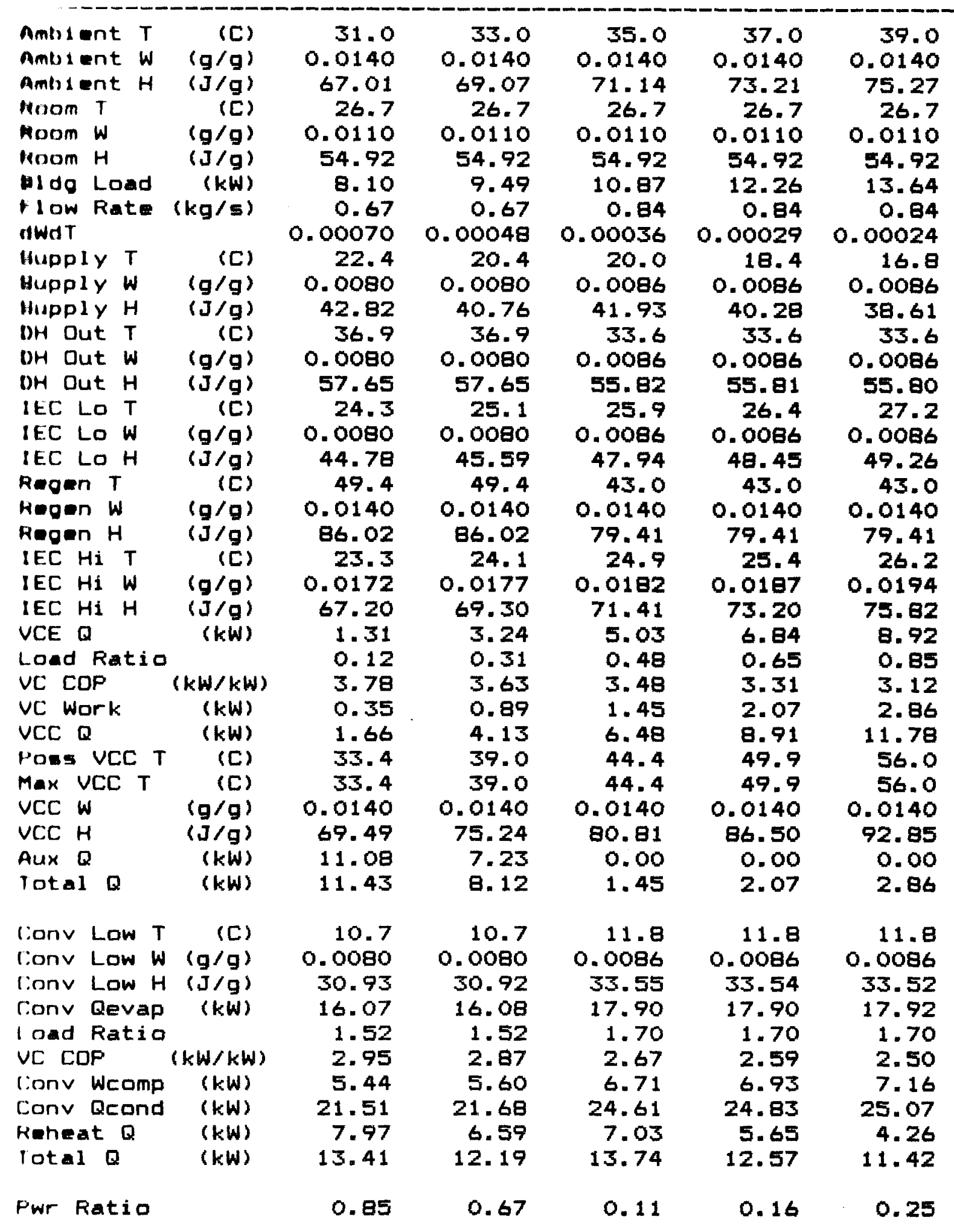




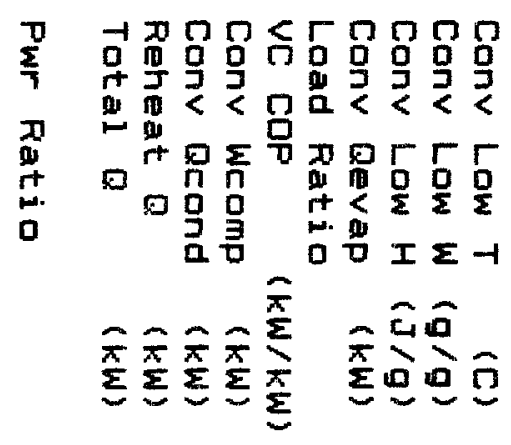

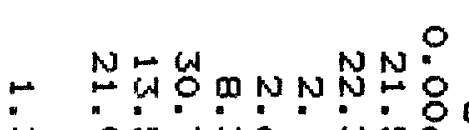

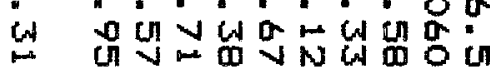

$\stackrel{8}{0}$

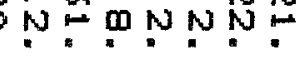

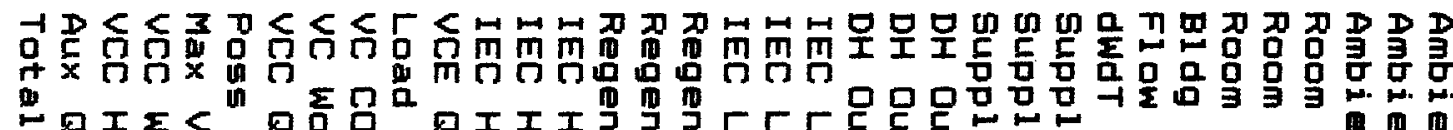

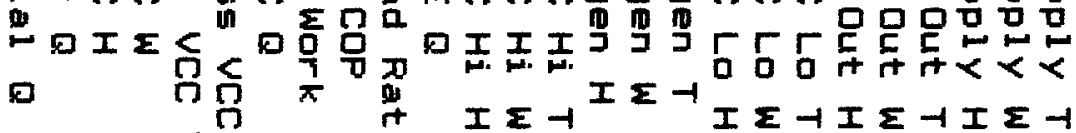

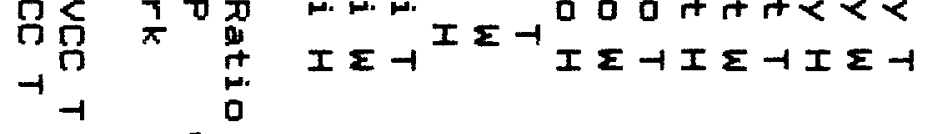

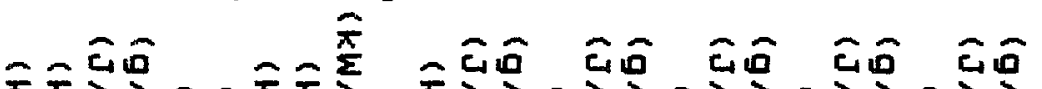

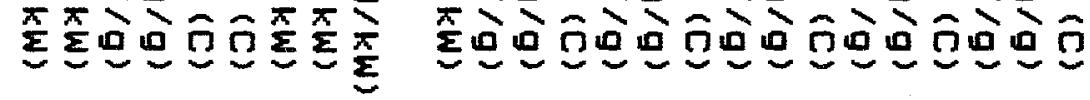

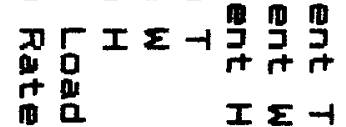

商人铂

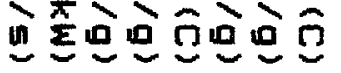

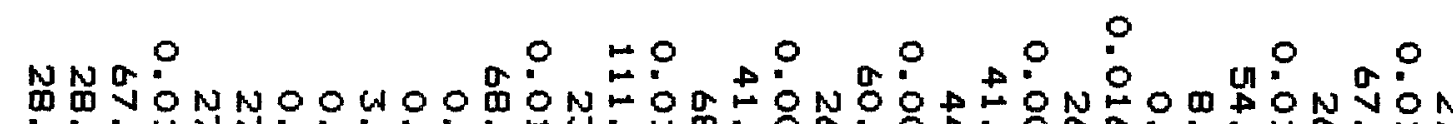
MU.

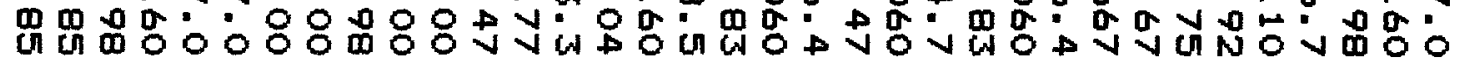

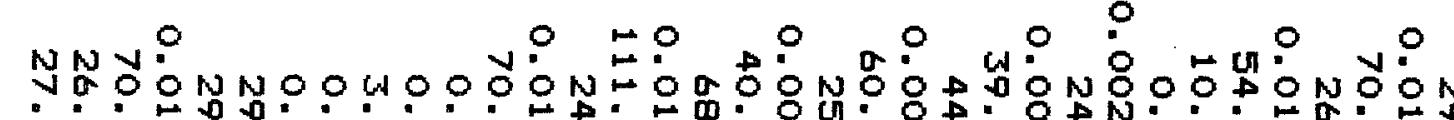

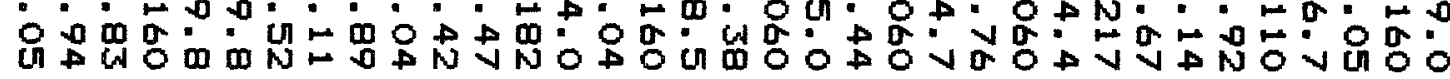

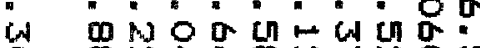

DNPOTNNNOU

- NMWONNAN

品

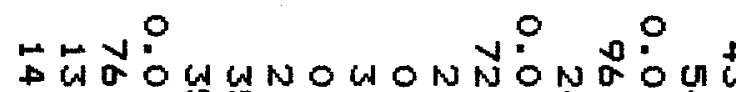

.

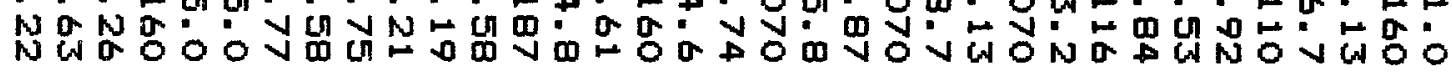

- NMTONNMNO

in $F$

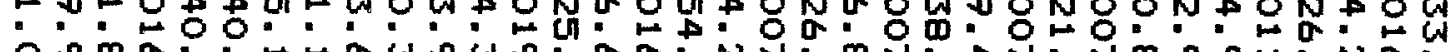

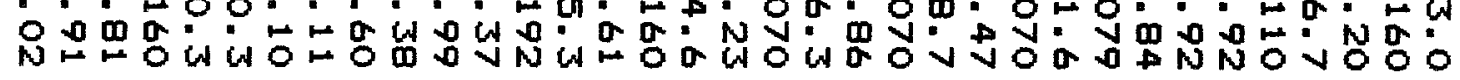

$\therefore$ Non $N$ cum

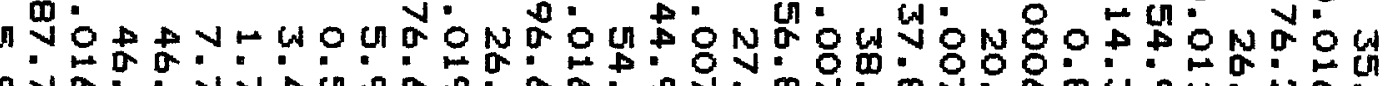

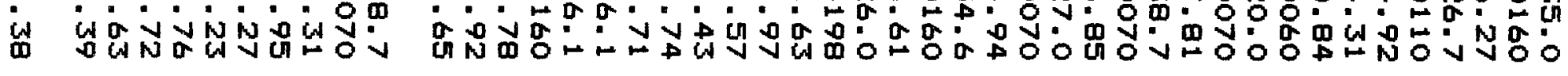


HYBRID SYSTEM ANALYSIS - SYstem 3

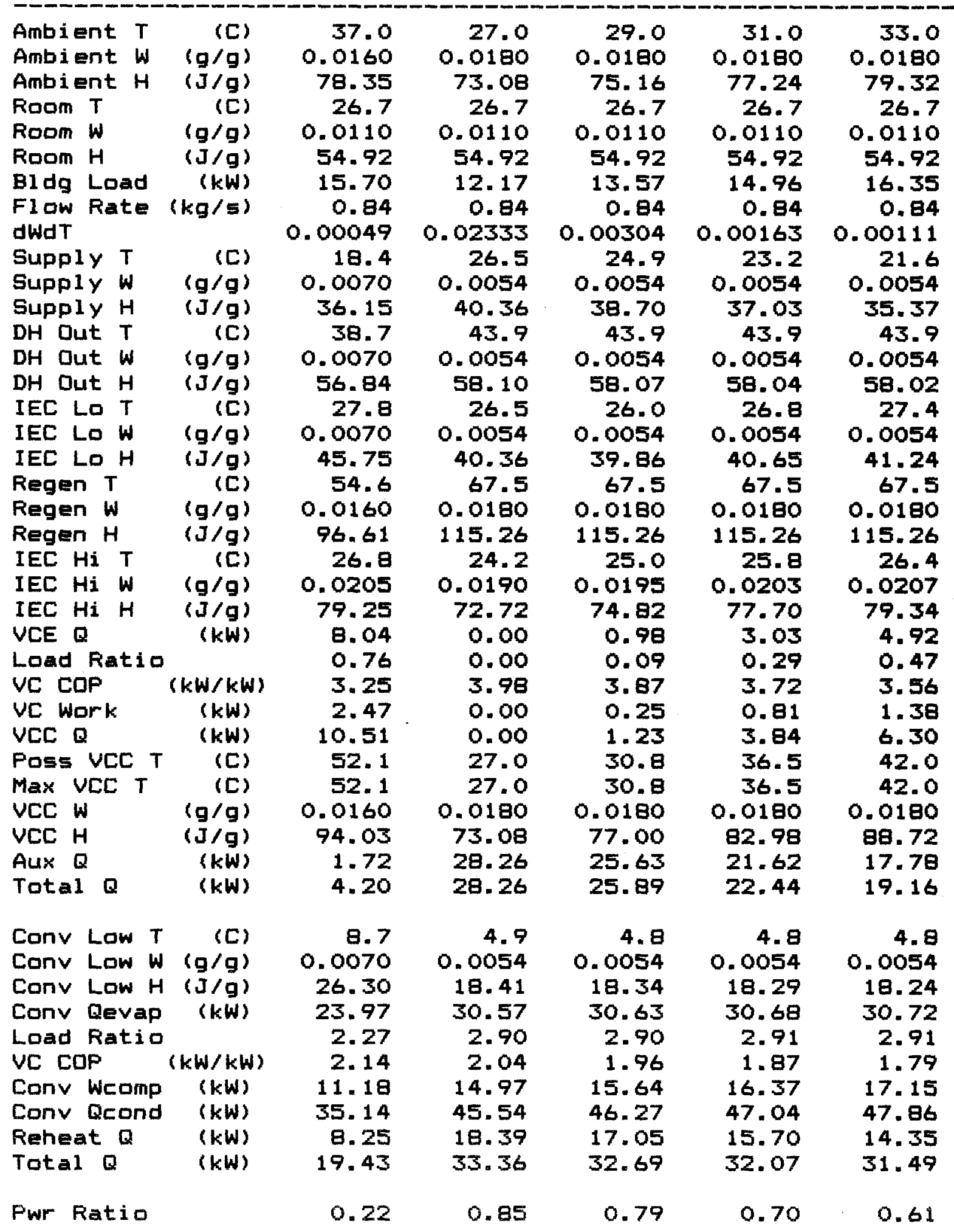


HYBRID SYSTEM ANALYSIS - SYgtem 3

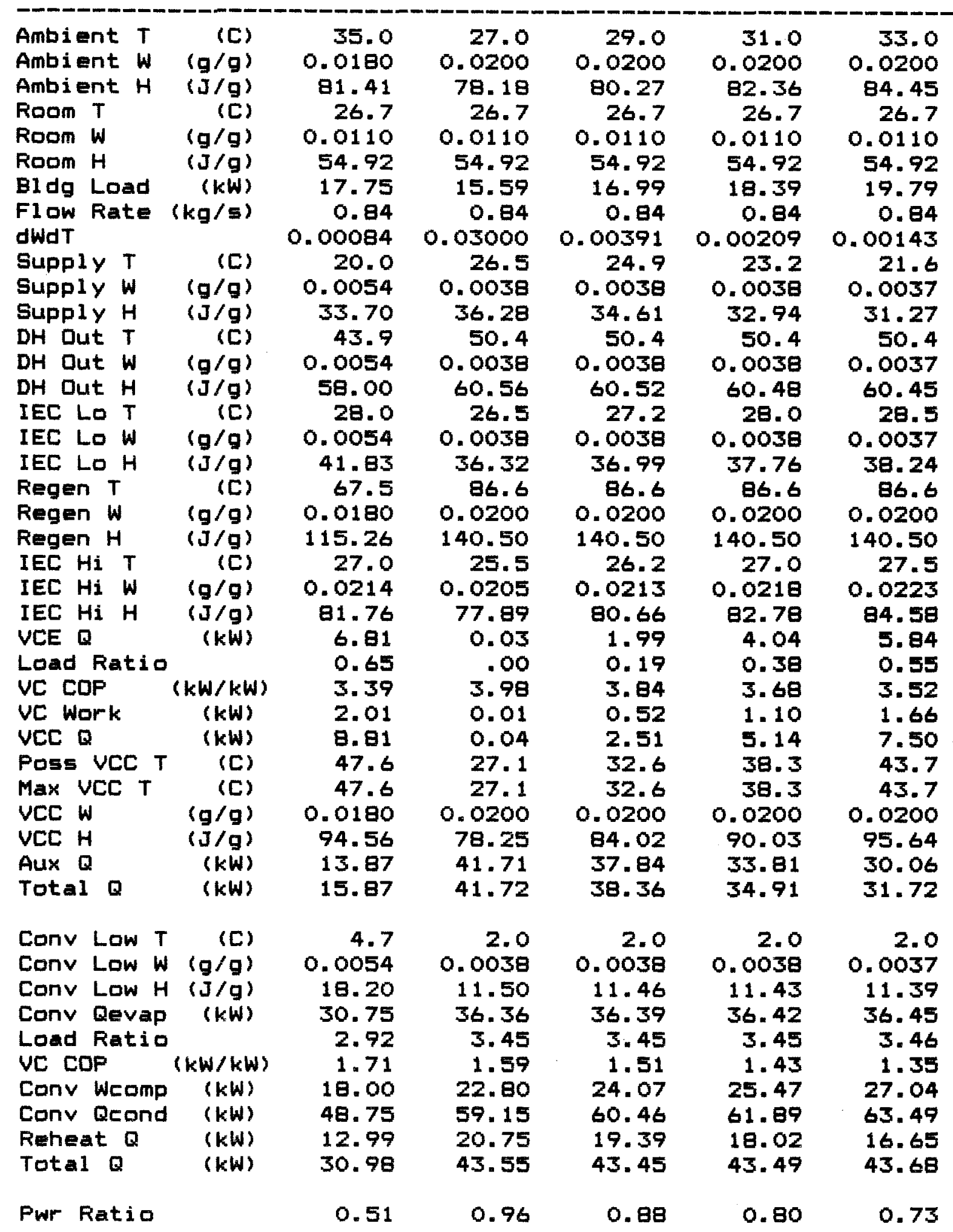


HYBRID SYSTEM ANALYSIS - SYstem 4

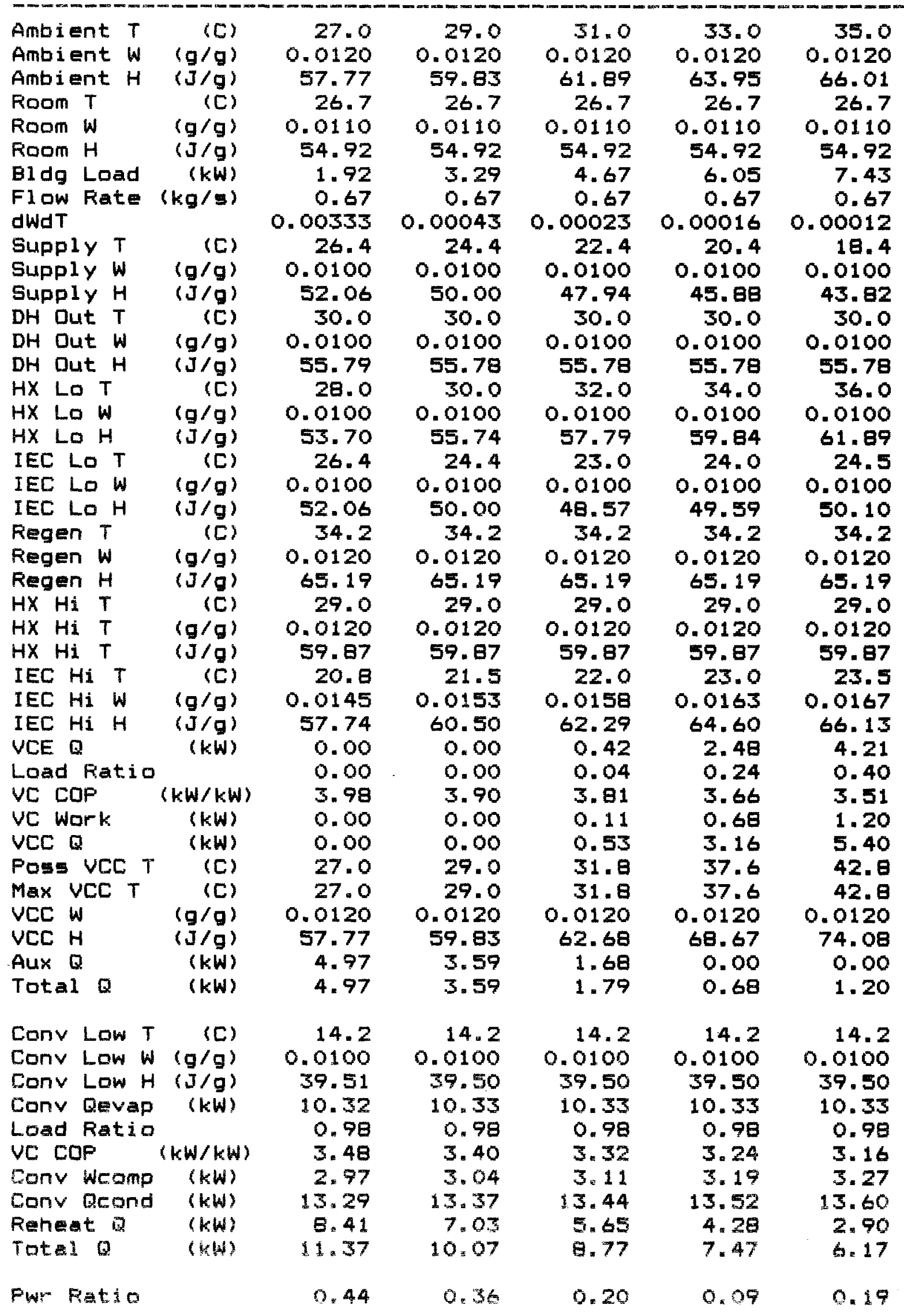


HYBRID SYSTEM ANALYSIS - SYstem 4

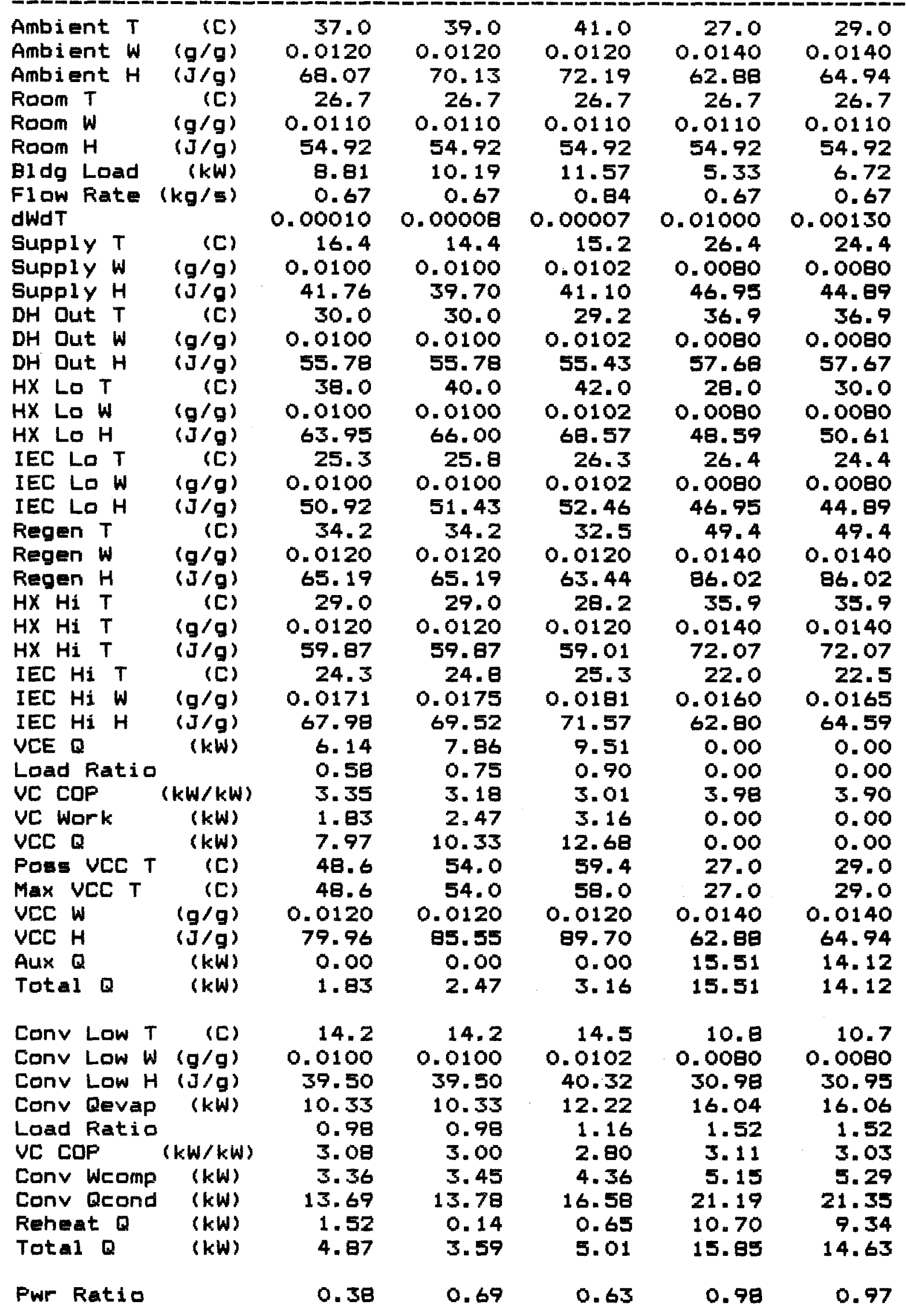




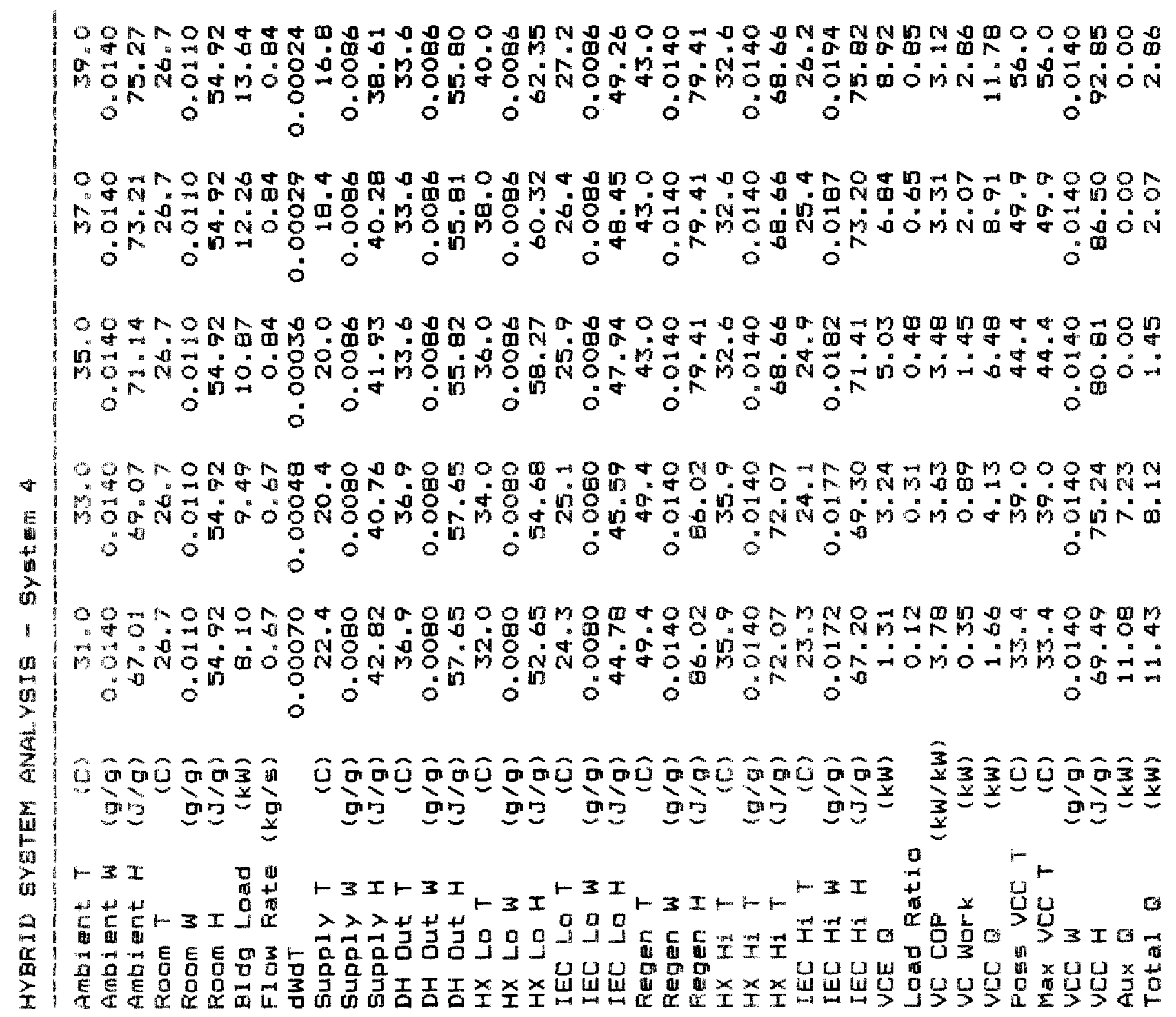

monogand - dud a d -

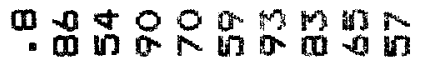

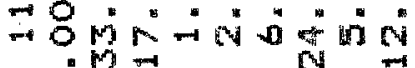
$b^{\circ}$ o

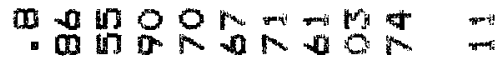
$\rightarrow 8 m a-4$

NONmNOHOa

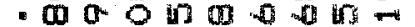
$\circ 80$ क

Nons 舟a 0 ing

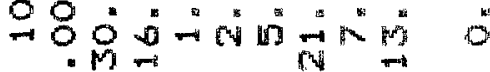
$0^{M} \rightarrow$

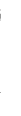

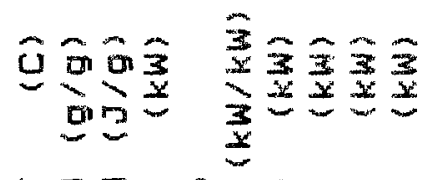
เ 3 工品是号

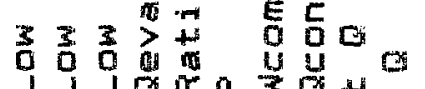

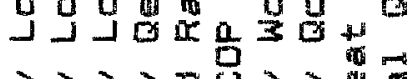
$\geq \geq \geq \geq 00 \geq \geq$ 告

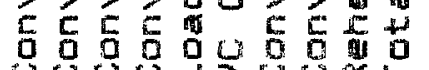


HYBRID SYSTEM ANALYSIS - SYStEm 4

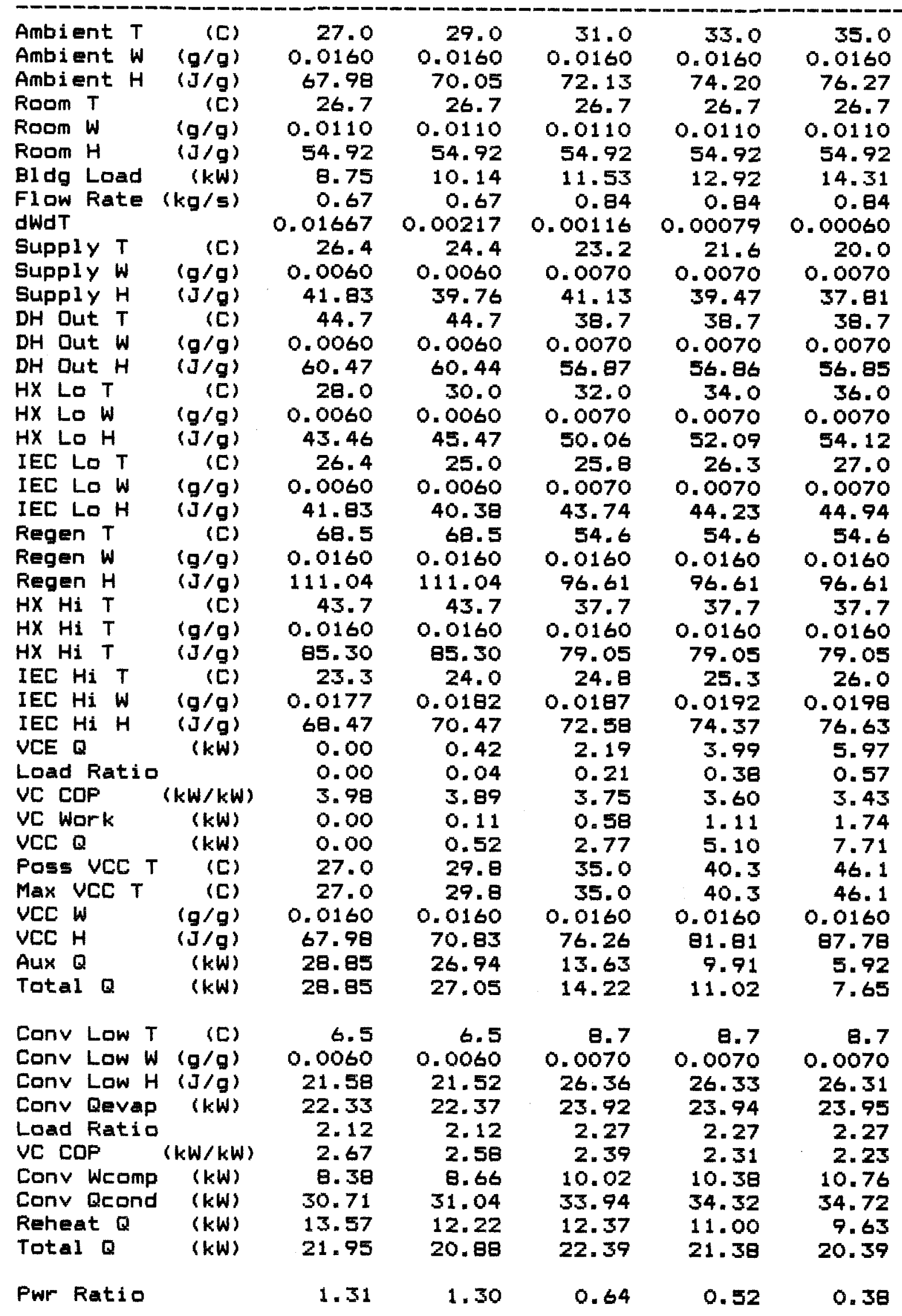


HYBRID SYSTEM ANALYSIS - SYstem 4

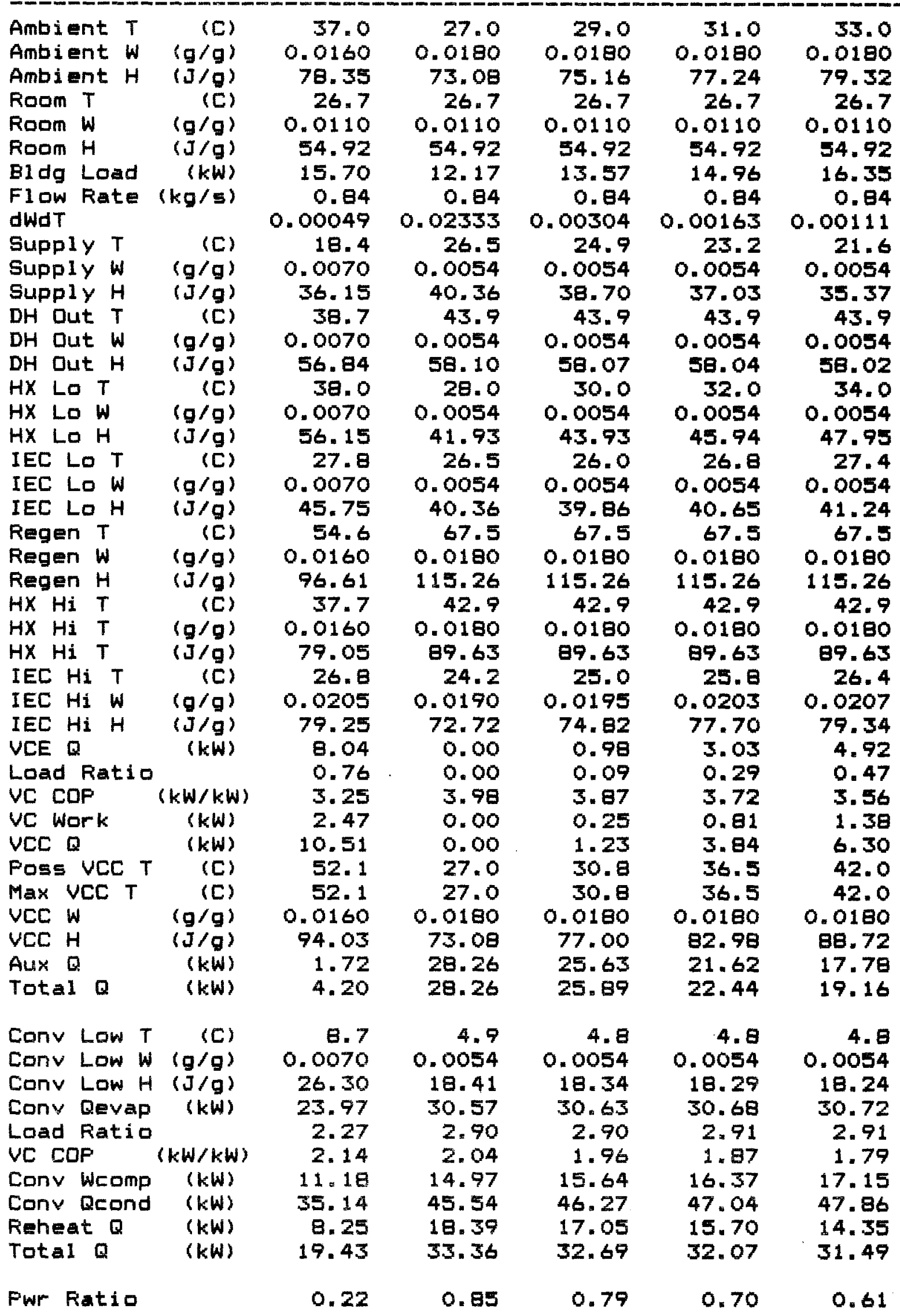


HYBRID SYSTEM ANALYSIS - SYStEm 4

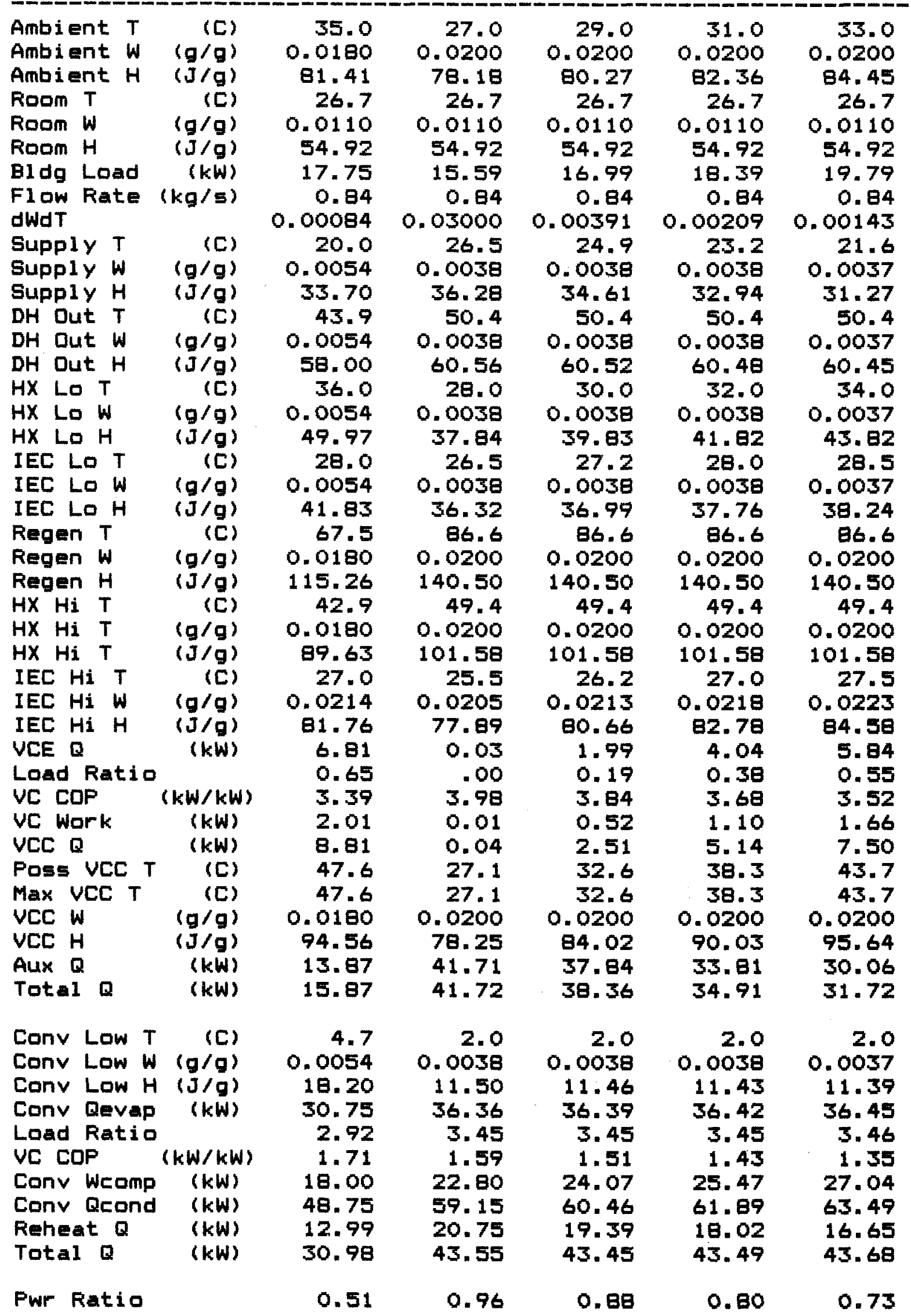




\section{SELECTED DISTRIBUTION LIST}

Kennard L. Bowlen

Cargocaire Engineering Corp. 79 Monroe St.

Amesbury, MA 01913

Jim Coellner, Director R\&E

American Solar King Corp.

700 Loop 340 South

Waco, TX 76710

Barry Cohen

Thermal Products Division

Thermo Electron Corporation

45 First Avenue

Waltham, MA 02154

Dr. Kirk Collier

Collier Engineering

Route 2, Box 240

Cave Creek, AZ 85331

Mr. Keith Davidson

Gas Research Institute

8600 West Bryn Mawr Avenue

Chicago, IL 60631

Mr. Robert Dikkers

National Bureau of Standards

Technology B-148

Washington, D.C. 20585

A. Hunter Fanney

Bldg. 226, Room B310

National Bureau of Standards

Washington, D.C. 20234

Mr. Anthony Fraioli

Argonne National Laboratory

9700 South Cass Avenue

Argonne, IL 60439

Mr. John Goldsmith

Route CE-311, Room 5H065

U.S. Department of Energy

1000 Independence Ave., S.W. Washington, D.C. 20585
R. Harkins

ASES

203017 th St.

Boulder, CO 80302

Richard B. Hayter

Engineering Extension

Ward Hall, Kansas State University

Manhattan, KS 66506

Wm. C. Irwin

Energy Demonstration \& Technology

Division

Electrical Utilization Group

Tennessee Valley Authority

1850 CUBB-C

Chattanooga, TN 37401

Ralph Johnson

NAHB Research Foundation, Inc. 3720 T St., N.W.

Washington, D.C. 20007

Robert Jones

Los Alamos National Lab

P.O. Box 1663

Mail Stop H577

Los Alamos, NM 87545

Dr. Susumi Karaki

Colorado State University

Fort Collins, CO 80523

K. LaPorta

SEIA

1156 15th St., N.W., Suite 520

Washington, D.C. 20005

Dr. Zalman Lavan

Illinois Institute of Technology

Department of Mechanical Engineering

Illinois Institute of Technology

Center

Chicago, IL 60616

Bob LeChevalier

U.S. Department of Energy

San Francisco Operations Office

1333 Broadway

Oakland, CA 94612 
Mr. Ian Maclaine-cross

University of New South Wales

School of Mechanical and Industrial

Engineering

P.O. Box 1

Kensington, NSW 2033 Australia

Gershon Meckler

G. M. A., P.C.

305 E. 40th St.

New York City, NY

Dr. John Mitchell

University of Wisconsin-Madison

Engineering Research Building

1500 Johnson Drive

Madison, WI 53706

Mr. Jeff Morehouse

Science Applications, Inc.

8400 Westpark Drive

McLean, VA 22101

Dr. Frederick Morse

U.S. Department of Energy

Route CE-31, Room 5H-095

1000 Independence Ave., S.W.

Washington, D.C. 20585

Stanley A. Mumma

104 Engineering "A" Building

University Park, PA 16802

Alwin B. Newton

136 Shelbourne Dr.

York, PA 17403

John E. Parks

Chemical Technology Division

Argonne National Laboratory

Argonne, IL 60439

Mr. John Schuler

Route CE-311, Room 5H065

U.S. Department of Energy

1000 Independence Ave., S.W.

Washington, D.C. 20585

Bill Seaton

ASHR AE

1791 Tullie Circle, NE

Atlanta, GA 30329
Dr. William Shertz

Argonne National Laboratory

9700 South Cass Avenue

Argonne, IL 60439

Mr. Morris Skalka

Route CE-311, Room 5H065

U.S. Department of Energy

1000 Independence Ave., S.W.

Washington, D.C. 20585

Dr. M. Wahlig

Lawrence Berkeley Laboratories

University of California

Berkeley, CA 94720

Mr. Alex Willman

ACEC Resource and Management Foundation

101515 th Street, N.W.

Washington, D.C. 20005

Dr. Byard Wood

Dept. of Mechanical \& Aerospace

Engineering

Arizona State University

Tempe, AZ 85287

M. Yarosh

Florida Solar Energy Center

300 State Road, 401

Cape Canaveral, FL 32920 


\begin{tabular}{|c|c|c|c|}
\hline $\begin{array}{l}\text { Document Control } \\
\text { Page }\end{array}$ & $\begin{array}{l}\text { 1. SERI Report No } \\
\text { SERI/TR-252-2527 }\end{array}$ & 2. NTIS Accession No. & 3. Recipient's Accession No. \\
\hline \multirow{2}{*}{\multicolumn{3}{|c|}{$\begin{array}{l}\text { 4. Title and Subtitle } \\
\text { Overview of Advanced Hybrid Desiccant Cooling } \\
\text { System }\end{array}$}} & $\begin{array}{l}\text { 5. Publication Date } \\
\text { October } 1984\end{array}$ \\
\hline & & & \\
\hline \multicolumn{3}{|c|}{$\begin{array}{l}\text { 7. Author(s) } \\
\text { Dennis Schlepp, Kenneth Schultz }\end{array}$} & 8. Performing Organization Rept. No. \\
\hline \multicolumn{3}{|c|}{$\begin{array}{l}\text { 9. Performing Organization Name and Address } \\
\text { Solar Energy Research Institute } \\
1617 \text { Cole Boulevard } \\
\text { Golden, Colorado } 80401\end{array}$} & $\begin{array}{l}\text { 10. Project/Task/Work Unit No. } \\
1600.23 \\
11 . \text { Contract (C) or Grant (G) No. } \\
\text { (C) } \\
\text { (G) }\end{array}$ \\
\hline \multirow{2}{*}{\multicolumn{3}{|c|}{ 12. Sponsoring Organization Name and Address }} & $\begin{array}{l}\text { 13. Type of Report \& Period Covered } \\
\text { Technical Report }\end{array}$ \\
\hline & & & 14. \\
\hline \multicolumn{4}{|l|}{ 15. Supplementary Notes } \\
\hline \multicolumn{4}{|c|}{$\begin{array}{l}\text { 16. Abstract (Limit: } 200 \text { words) } \\
\text { This report describes an assessment of the energy savings possible from develop- } \\
\text { ing hybrid desiccant/vapor-compression air conditioning systems. Recent } \\
\text { advances in dehumidifier design for solar desiccant cooling systems have resulted } \\
\text { in a dehumidifier with a low pressure drop and high efficiency in heat and mass } \\
\text { transfer. A recent study on hybrid desiccant/vapor compression systems showed } \\
\text { a } 30 \%-80 \% \text { savings in resource energy when compared with the best conventional } \\
\text { systems with vapor compression. A system consisting of a dehumidifier with } \\
\text { vapor compression subsystems in series was found to be the simplest and best } \\
\text { overall performer. }\end{array}$} \\
\hline \multirow{3}{*}{\multicolumn{4}{|c|}{$\begin{array}{l}\text { 17. Document Analysis } \\
\text { a. Descriptors Dehumidifiers; Dehumidification ; Desiccants ; Evaporative Cooling ; } \\
\text { Heat Exchangers; Hybrid Systems; Solar Cooling Systems ; Vapor } \\
\text { Compression Refrigeration Cycle } \\
\text { b. Identifiers/Open-Ended Terms } \\
\text { c. UC Categories } \\
59 a\end{array}$}} \\
\hline & & & \\
\hline & & & \\
\hline \multirow{2}{*}{\multicolumn{3}{|c|}{$\begin{array}{l}\text { 18. Availability Statement } \\
\text { National Technical Information Service } \\
\text { U.S. Department of Commerce } \\
5285 \text { Port Royal Road } \\
\text { Springfield, Virginia } 22161\end{array}$}} & $\begin{array}{r}\text { 19. No. of Pages } \\
56\end{array}$ \\
\hline & & & $\begin{array}{l}\text { 20. Price } \\
\mathrm{AO4}\end{array}$ \\
\hline
\end{tabular}

